\title{
CHOQUES NO SPREAD DE CRÉDITO BANCÁRIO E SUAS IMPLICAÇÕES PARA A CONDUÇÃO DA POLÍTICA MONETÁRIA NO BRASIL
}

\author{
André Francisco Nunes de Nunes * \\ Marcelo Savino Portugal ${ }^{+}$
}

\begin{abstract}
Resumo
O trabalho busca analisar a transmissão dos choques no spread de crédito bancário para as demais variáveis da economia e suas implicações para a condução da política monetária no Brasil. Para isso, foi estimado um modelo DSGE com fricções financeiras. A inclusão do spread de crédito não altera a resposta do modelo DSGE em relação aos choques exógenos tradicionais. Porém, quando existem choques exógenos sobre o spread de crédito, o impacto sobre o ciclo econômico foi significativo e a adoção de uma regra de política monetária ajustada pelo spread pode estabilizar a economia mais rapidamente.
\end{abstract}

Palavras-chave: DSGE, Mercado de Crédito; Fricções Financeiras; Política Monetária.

\begin{abstract}
This paper seeks to analyze the transmission of shocks in the banking credit spread for the other variables of the economy and its implications for the conduct of monetary policy in Brazil. We do so by estimating a DSGE model with financial frictions. The inclusion of credit spread does not significantly changes the DSGE model responses to traditional exogenous shocks. However, in the case of shocks on the credit spread, the impact on the business cycle was significant and a monetary policy rule set by the spread can achieve a faster stabilization of the economy than a traditional rule.
\end{abstract}

Keywords: DSGE; Credit Market; Financial Frictions; Monetary Policy. JEL classification: E52, E32, E44.

DOI: http://dx.doi.org/10.11606/1980-5330/ea130574

\footnotetext{
${ }^{*}$ Economista-Chefe do Sistema FIERGS e aluno de doutorado do PPGE/UFRGS. Email: andrefnnunes@gmail.com.

† Professor do PPGE/UFRGS e do PPGA/UFRGS e pesquisador do CNPq.
} 


\section{Introdução}

Os modelos DSGE, em geral, utilizam baixa, ou nenhuma, fricção no mercado financeiro, e devido à possibilidade de arbitragem, as taxas de juros de maturidades semelhantes convergem para o mesmo valor. Assim, a existência de uma única taxa de juros é suficiente para representar uma economia sem fricções financeiras. Nesse caso, a taxa de juros precisa assumir papéis diversos: de taxa básica de operação da política monetária, taxa de retorno de todas as famílias e firmas por poupar e taxa a que qualquer agente pode tomar emprestado contra a renda futura.

Nesse arcabouço, o próprio comportamento maximizador das famílias e das firmas faz com que os fluxos gerados pelas empresas cheguem até as famílias sem a necessidade de fluxos de crédito em equilíbrio. Portanto, as perturbações no mercado de crédito e as variações no spread bancário não têm impactos na alocação de recursos da economia.

Porém, mais recentemente, diversos trabalhos procuraram reexaminar as evidências sobre a relação entre os spreads de crédito e da atividade econômica, principalmente colocando os insights da crise de 2008 como, por exemplo, as recessões que têm como origem um choque no setor financeiro. Para isso, os modelos teóricos, em especial os modelos DSGE, passaram por aprimoramentos para incorporar a possibilidade da existência de mais de uma taxa de juros na economia, bem como a transmissão das perturbações no spread para as demais variáveis do modelo.

A crise internacional também colocou questionamentos sobre a condução da política monetária tradicional. O limite zero da taxa de juros e as medidas alternativas, como aquelas de quantitative easing ganharam espaço na discussão teórica e empírica. Os trabalhos de McCulley \& Toloui (2008) e Taylor et al. (2008), ao observarem o mercado de crédito, identificaram que um primeiro indicador nos momentos de estresse no mercado financeiro é o aumento do spread entre as taxas de juros de referência para a política monetária e aquela pela qual os consumidores tomam emprestado e que a política monetária tradicional não consegue dar respostas satisfatórias. Diante disso, esses autores levantaram a hipótese de que uma Regra de Taylor ajustada pelos movimentos no spread seria uma forma adequada para a condução da política monetária em momentos de estresse no mercado financeiro. Porém, coube a Cúrdia \& Woodford (2010) formular um modelo e testar o comportamento dessa alternativa para a política monetária.

Assim, Cúrdia \& Woodford (2010) propuseram uma extensão do modelo de Woodford \& Walsh (2003) para incorporar a existência de um diferencial entre as taxas de juros disponíveis aos poupadores e tomadores de empréstimos, que pode variar por razões tanto endógenas quanto exógenas. Nesse modelo, mesmo em equilíbrio haverá spread entre as taxas de juros, e variações no grau de endividamento dos agentes, consumidores e governo produzem efeitos alocativos. Nessa economia, a política monetária, por sua vez, pode responder não somente às variações na taxa de inflação e hiato do produto por meio de uma regra simples, como também por meio de uma regra ajustada pelo spread de crédito da economia.

Segundo os autores, é plausível imaginar que a variação no spread bancário possui efeitos na alocação de recursos da economia. Mesmo nas economias com sistema financeiro mais avançado, verifica-se grande diferença entre os spreads, bem como uma variação destes ao longo do tempo, principalmente 
nos períodos de estresse financeiro. Nesse contexto, um aperto monetário, seja ele resultado direto da política monetária ou de fatores exógenos, está relacionado com variações nos spreads, bem como com a redução real no dispêndio e aumento no desemprego da economia.

Do ponto de vista teórico, o modelo de Cúrdia \& Woodford (2010) se diferencia daqueles que seguem a linha de Bernanke \& Gertler (1989) porque há mais de um agente consumidor e as fricções ocorrem no âmbito das famílias, sendo que a estrutura das firmas permanece semelhante à do modelo Keynesiano tradicional. Na literatura de modelos DSGE com fricções financeiras, trabalhos com foco no crédito para as famílias são mais escassos em comparação àqueles que tratam do prêmio de financiamento externo para as firmas. Nessa linha, destacam-se os trabalhos de Goodfriend \& McCallum (2007), que conseguiram incorporar múltiplas taxas de juros em um modelo DSGE de pequena escala, e De Fiore \& Tristani (2011), os quais também elaboraram um modelo com mercado de crédito em que a taxa pela qual os agentes tomam emprestado é distinta da taxa de juros da política monetária. O modelo de Cúrdia \& Woodford (2010) utilizou diversos elementos desses trabalhos anteriores para criar um modelo mais complexo, com dois tipos de agentes consumidores dentro da estrutura dos modelos Novos Keynesianos.

No caso do Brasil, a literatura que busca analisar a formação e os determinantes dos spreads bancários é bastante consolidada. Um dos trabalhos pioneiros nessa linha foi elaborado por Aronovich (1994), que estimou os efeitos da taxa de inflação e da atividade econômica sobre o spread e indicou que a inflação tende a aumentar a diferença entre a taxa básica de juros e as taxas praticadas no mercado de crédito. Já Afanasieff et al. (2002) utilizam dados macro e microeconômicos para explicar os movimentos do spread no Brasil e sugerem que as variáveis macro, como inflação e variações no produto, são as mais relevantes para explicar o comportamento do spread.

Na literatura de modelos DSGE aplicados à economia brasileira é possível destacar trabalhos que buscam inserir os intermediários financeiros como um agente econômico. Costa (2011), desenvolveu um modelo DSGE de médio porte com um setor bancário. A existência de fricções financeiras implica passthrought imperfeito da política monetária, atenuando os efeitos do choque monetário, por conta da formação do custo marginal bancário e da estrutura de mercado adotada. Nessa mesma linha, Aranha (2012) incorporou o setor bancário num modelo DSGE com fricções financeiras para a economia brasileira e avaliou o impacto nos preços, produto, investimento e consumo. O autor aponta que a redução das fricções financeiras teriam uma influência positiva no investimento, consumo e produto. Entretanto, a elevação dos spreads ajudaria a conter o avanço nos níveis de preços em decorrência de choques na economia brasileira.

Os trabalhos de Santin (2013), Carvalho et al. (2013), e Nunes \& Portugal (2015) também utilizaram uma modelagem para o setor financeiro com o objetivo mais específico de investigar o papel das políticas monetárias não tradicionais na condução da política monetária. No caso de Santin (2013), uma das principais conclusões é que a introdução das fricções financeiras e de políticas de crédito e compulsório piorou a potência da política monetária, em que pese a diminuição da amplitude do ciclo econômico. No trabalho de Carvalho et al. (2013), os autores mostram que o impacto da política monetária no lado real da economia é substancialmente maior do que no caso em que se utiliza as políticas não tradicionais. Entretanto, eles mostram que em cenários mais 
extremos, em que o capital dos bancos está severamente debilitado, a injeção de capital nos bancos pode mitigar substancialmente os impactos da escassez de crédito na economia real. Nesse contexto, Nunes \& Portugal (2015) estimaram com dados da economia brasileira um modelo DSGE com instituições financeiras para analisar os impactos das políticas não tradicionais na condução da política monetária. As conclusões apontaram para a maior eficiência da política monetária tradicional para estabilizar a economia. Embora, uma política de crédito se mostre mais efetiva para mitigar os efeitos de uma crise financeira.

Entretanto, a metodologia proposta por Cúrdia \& Woodford (2010), e que será utilizada como referência nesse trabalho, não faz a modelagem do sistema financeiro como um agente econômico, as fricções financeiras surgem do custo de transação entre poupadores e tomadores, o que gera modelos de menor escala. Nessa linha, destaca-se o trabalho de Kanczuk (2013), que elabora um modelo DSGE aplicado à economia brasileira com o objetivo de avaliar as políticas macroprudenciais. O modelo utiliza elementos de Bernanke et al. (1999) e Cúrdia \& Woodford (2010) e o trabalho tem o objetivo de extrair os prêmios de financiamento externo para as famílias e firmas e comparar com os dados de crédito.

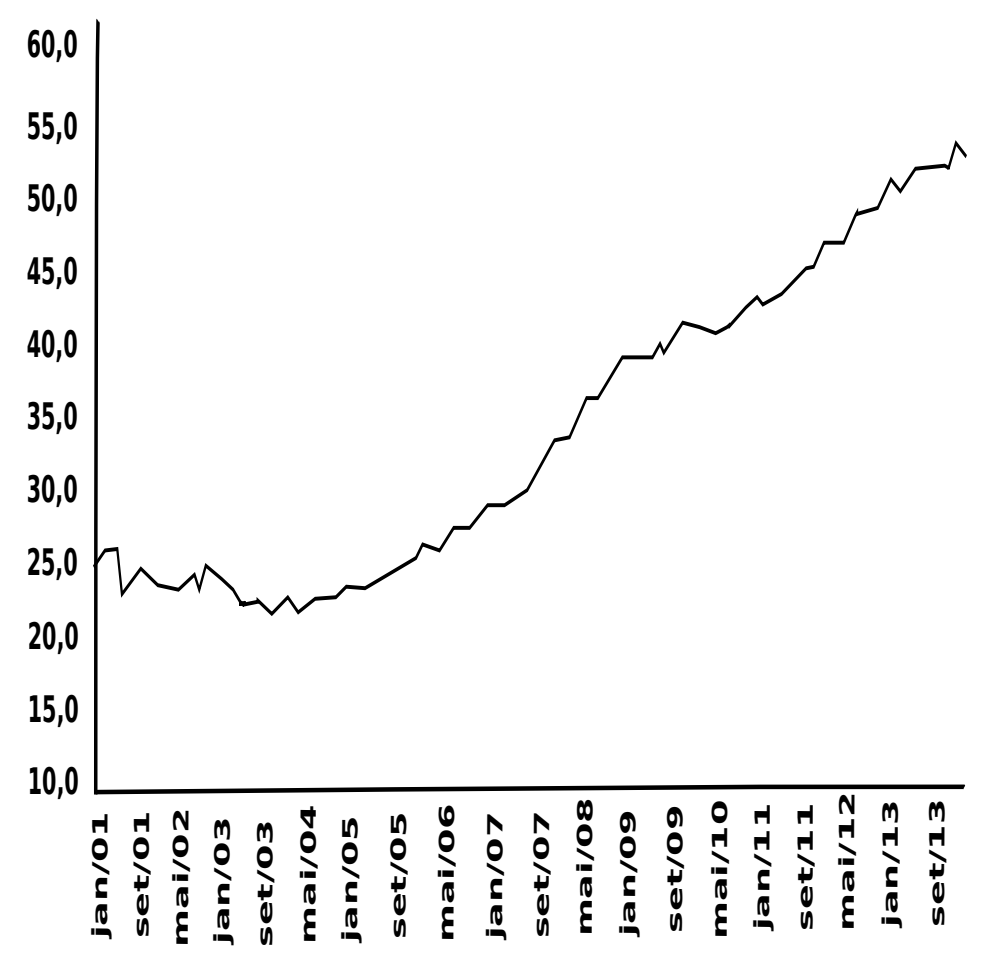

Fonte: Banco Central do Brasil (2014).

Figura 1: Saldo real das operações de crédito ao setor privado em relação ao PIB

Ainda dentro da metodologia de Cúrdia \& Woodford (2010), Vega Filho (2013) realizou simulações com parâmetros calibrados para economia brasileira. O trabalho verificou que o endividamento dos agentes aumenta mais no modelo com fricções, em comparação com o modelo sem fricções financeiras 
em resposta a um choque exógeno de política monetária. Esse comportamento decorreu da maior sensibilidade do endividamento à queda na atividade e ao aumento no spread de crédito. Nesse modelo, o aumento na taxa de juros determinada pelo Banco Central, que é a mesma taxa de captação do sistema financeiro, aumenta menos do que proporcionalmente em relação ao aumento na taxa de juros para os tomadores finais, em decorrência da queda na atividade e dos custos de intermediação, o que explica o aumento no spread de crédito.

A análise do papel do spread de crédito nos ciclos econômicos ganha importância no contexto da economia brasileira na medida em que houve forte expansão do crédito e redução dos spreads entre as taxas de juros durante a última década. A Figura 1 mostra a participação do crédito na economia, que dobrou de tamanho, passando de 26,1 pontos percentuais de participação no PIB em janeiro e 2001 para 53,0 em janeiro de 2014. Essa transformação é positiva na medida em que possibilita o crescimento nos investimentos privados, a suavização do consumo no tempo e o alongamento do horizonte de planejamento dos agentes.

Por outro lado, abre-se espaço para que as oscilações no sistema financeiro tenham impactos potenciais mais significativos no lado real da economia. A Figura 2 mostra o comportamento cíclico do spread médio mensal das operações de crédito com recursos livres e observa-se também que os picos ocorrem em momentos de recessão e maior incerteza econômica. Dessa forma, se considerada a hipótese de que as oscilações nessa variável possuem efeitos reais e de alocação, o aumento da participação do crédito na economia brasileira pode significar uma fonte a mais de perturbação dos ciclos econômicos. Portanto, essa característica motiva o estudo dos impactos potenciais das variáveis de crédito sobre as demais variáveis macroeconômicas, bem como sobre a condução da política monetária.

O objetivo deste artigo será estimar o modelo de Cúrdia \& Woodford (2010) para a economia brasileira e analisar o comportamento da economia frente a diferentes perturbações exógenas do modelo com fricções financeiras e a sua versão sem essas fricções. Os choques nas variáveis que influenciam o spread de crédito terão como variáveis de resposta o produto, taxa de inflação, taxa de juros, spread e endividamento das famílias. Além disso, será estimada a regra de política monetária ótima do modelo com spread e avaliar o desempenho da política monetária conduzida a partir de uma regra ajustada pelo spread.

Na próxima seção será apresentado o modelo de Cúrdia \& Woodford (2010). Na segunda seção será realizada a estimação do modelo com fricções financeiras por métodos Bayesianos, o qual será comparado com o modelo sem fricções financeiras. Na terceira seção serão realizadas as simulações de impulso e resposta dos modelos com e sem fricções financeiras. Em seguida, na quarta parte do trabalho, será apresentado o problema de minimização da função de perda do Banco Central no modelo com fricções financeiras. Na quinta seção consta a proposta para uma Regra de Taylor ajustada pelo spread, na qual a autoridade monetária leva em conta as variações no spread para a condução da política monetária. A última parte será destinada às considerações finais. 


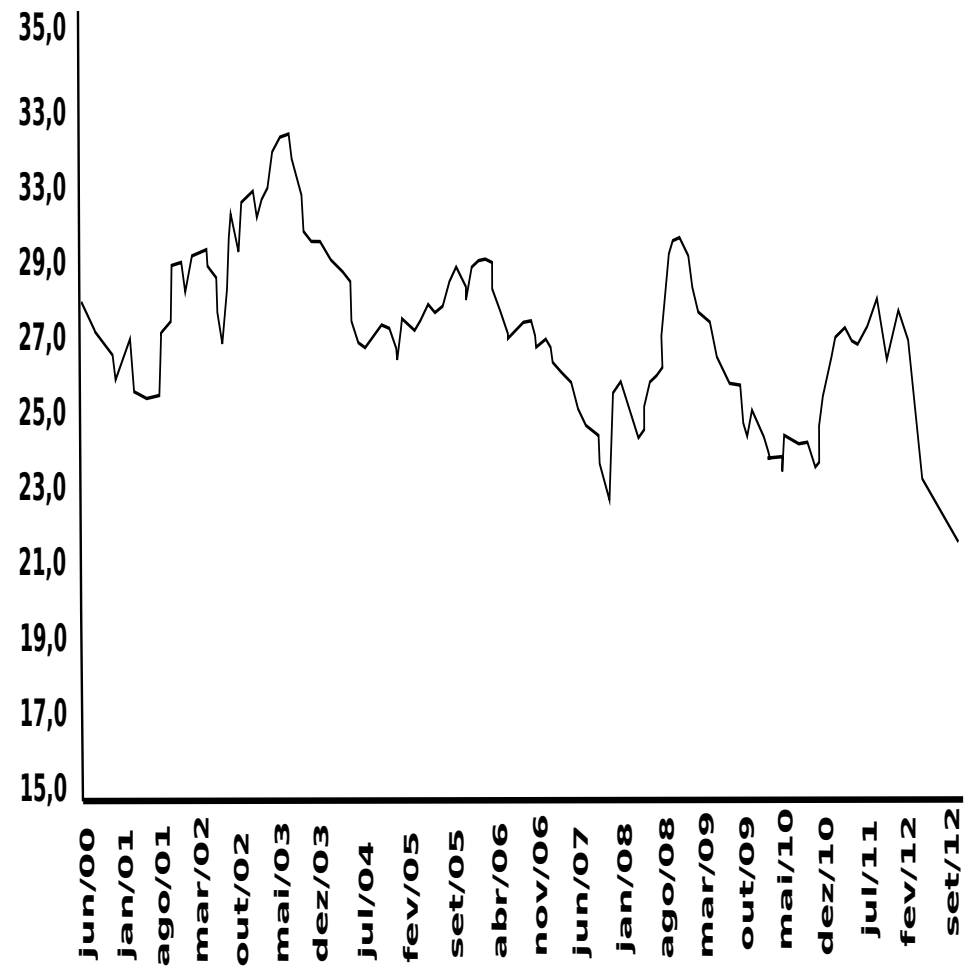

Fonte: Banco Central do Brasil (2014). *Pré-fixado, pós-fixado e flutuante.

Figura 2: Spread médio mensal das operações de crédito com recursos livres $^{*}-\%$ ao ano

\section{O modelo Novo Keynesiano com spread nas taxas de juros}

Esta seção apresentará o modelo com fricções financeiras de Cúrdia \& Woodford (2010) que foi formulado tendo como base Woodford \& Walsh (2003). A apresentação dará mais ênfase à parte dos consumidores, que é onde há uma diferenciação em relação à literatura tradicional e são inseridas as fricções financeiras. As demais partes seguem a literatura tradicional semelhante ao apresentado em Woodford \& Walsh (2003) e serão apresentadas de maneira mais breve.

O modelo assume a hipótese de que as instituições financeiras captam os seus recursos por meio dos depósitos do público com um custo equivalente à taxa de juros utilizada como instrumento de política monetária pelo Banco Central. Contudo, a taxa para os tomadores finais será diferente da taxa fixada pela autoridade monetária. Os tomadores pagarão um spread sobre a taxa básica, que refletirá as fontes de friç̧ões financeiras do modelo, tais como custos de transação e choques exógenos sobre as condições financeiras dos agentes da economia.

Ao longo do trabalho os termos spread de crédito e spread bancário serão utilizados como sinônimos. O spread é entendido como a diferença entre a taxa de juros dos empréstimos e a taxa de captação. No modelo, a taxa de captação das instituições financeiras será a taxa básica de juros da economia, que será a remuneração da poupança das famílias.

Nesse modelo, os consumidores são heterogêneos e se dividem entre pou- 
padores e tomadores de empréstimos. Contudo, não existe um estado imutável para cada tipo de agente. Uma família poupadora pode se transformar em tomadora de crédito e vice-versa. O bem estar auferido da despesa com consumo é diferente para cada família $i$, que busca maximizar o valor presente da sua função de utilidade que apresenta a seguinte forma:

$$
E_{0} \sum_{t=0}^{\infty} \beta^{t}\left[u^{\tau_{t}(i)}\left(c_{t}(i) ; \xi_{t}\right)-\int_{0}^{1} v\left(h_{t}(j ; i) ; \xi_{t}\right) d_{j}\right]
$$

em que $\tau_{t}(i) \in(b, s)$ indica o tipo de cada família, tomadora ou emprestadora, no tempo $t$. Assim, haverá duas funções de utilidade $u^{b}(c ; \xi)$ e $u^{s}(c ; \xi)$, que estarão sujeitas a um vetor de choques aleatórios $\xi_{t}$. A economia conta com um contínuo de bens de consumo diferenciados, $c_{t}(i)$, que são ofertados pelas firmas num mercado de concorrência monopolística e agregados na metodologia de Dixti-Stiglitz. De maneira semelhante, as famílias ofertam mão de obra especializada $j(i)$ e são contratadas pelas firmas. Além disso, a função de utilidade aditiva conta com uma desutilidade no trabalho, $v(h ; \xi)$, que é a mesma para todos os agentes e está sujeita à choques aleatórios, $\xi_{t}$.

O tipo de cada agente $\tau_{t}(i)$ evolui de acordo com um processo de Markov com dois estados. Em cada período existe a probabilidade $1-\delta$ (com $0 \leq \delta<1$ ) de o agente assumir um novo tipo e, caso contrário, ele permanecerá com o mesmo tipo do período anterior. Portanto, o agente assume o tipo $b$ com probabilidade $\pi_{b}$ e o tipo $s$ com probabilidade $\pi_{s}$, de forma que $0<\pi_{b}, \pi_{s}<1 e \pi_{b}+\pi_{s}=1$. Também se assume que $u_{c} b(c ; \xi)>u_{c} s(c ; \xi)$ para todos os níveis de consumo, $c$. Isso implica que uma mudança no tipo da família altera a sua propensão a consumir, dado o choque $\xi$, e a família poupadora tem uma menor propensão a consumir em comparação com a família tomadora de crédito. No caso de $u_{c} b(c ; \xi)=u_{c} s(c ; \xi)$ para todos os períodos, teremos uma abordagem tradicional, na linha do modelo Novo Keynesiano de Woodford \& Walsh (2003).

As famílias estão aptas a gastar uma quantidade diferente de sua renda atual optando por depositar em fundos remunerados por uma taxa de juros ou pegar emprestado de intermediários financeiros. A mesma taxa de juros nominal está disponível para todos os poupadores, e uma taxa de juros diferente estará disponível para todos os tomadores de empréstimos. Isso vale independentemente das quantidades que uma determinada família escolhe para poupar ou tomar emprestado. Evidentemente, para garantir a existência das instituições financeiras, as famílias só poderão realizar operações de crédito com o intermediário financeiro, não é possível que uma família contrate um empréstimo da outra diretamente.

Um problema potencial para esse tipo de modelo surge do histórico de consumo de cada família quando o tempo vai para o infinito, o que dificulta a agregação e obtenção de um steady-state. Para impedir que as utilidades das famílias se tornem muito dispersas ao longo do tempo, os autores conseguem uma saída elegante ao propor um contrato financeiro adicional. As famílias podem assinar contratos umas com as outras e receber recursos contra o risco agregado e o risco associado ao seu tipo sorteado. Porém, esse evento não é contínuo e em todos os outros períodos ela deverá transacionar com o intermediário financeiro.

Assumindo o mecanismo acima, Cúrdia \& Woodford (2009), mostram que existe um equilíbrio em que cada agente do tipo $s$ tem uma poupança positiva, 
enquanto cada agente do tipo $b$ tem um empréstimo em cada período. Como conseqüência, a taxa de juros que é relevante para a decisão intertemporal para um tipo de família passa a ser perfeitamente correlacionada com o tipo da família. Além disso, o mecanismo do seguro garante que independentemente das suas histórias passadas, em qualquer período, todas as famílias de um determinado tipo têm a mesma utilidade marginal da renda.

Assumindo essa estrutura, haverá uma equação de Euler que satisfaz cada processo. Sendo $\lambda_{t}^{\tau}$ a utilidade marginal da renda real das famílias do tipo $\tau$, em que $\tau_{t}(i) \in(b, s)$, a equação que mostra a evolução em estado estacionário para a renda das famílias pode ser descrita por dois processos estocásticos $\hat{\lambda}_{t}^{b}, \hat{\lambda}_{t}^{s}$ :

$$
\begin{aligned}
& \hat{\lambda}_{t}^{b}=\hat{i}_{t}^{b}-E_{t} \pi_{t+1}+\left(\delta+(1-\delta) \pi_{b}\right) \hat{\lambda}_{t+1}^{b}+(1-\delta) \pi_{s} \hat{\lambda}_{t+1}^{s} \\
& \hat{\lambda}_{t}^{s}=\hat{i}_{t}^{d}-E_{t} \pi_{t+1}+\left(\delta+(1-\delta) \pi_{s}\right) \hat{\lambda}_{t+1}^{s}+(1-\delta) \pi_{b} \hat{\lambda}_{t+1}^{b}
\end{aligned}
$$

A seguinte notação foi utilizada para as variáveis em estado estacionário: $\lambda_{t}^{\tau}=\log \left(\lambda_{t}^{\tau} / \bar{\lambda}^{\tau}\right.$ para $\tau=b, s ; \hat{i}_{t}^{m}=\log \left(1+i_{t} / 1+\bar{i}\right)$ para $m=b, d$ e $\pi=\log \left(\prod_{t}\right)$. A barra acima das variáveis indica o seu valor em estado estacionário, conforme descrito no Apêndice 6.

As Equações (2) e (3) mostram que cada tipo de família está sujeito a uma taxa de juros diferente. No primeiro caso, $i_{t b}$ é a taxa de juros oferecida para os tomadores de crédito pelas instituições financeiras no período $t$ para ser paga no início do período $t+1$. Por sua vez, os poupadores recebem a taxa de juros livre de risco, $i_{t d}$, no início do período $t+1$ sobre a poupança depositada no final do período $t$.

O sistema de Equações (2) e (3) pode ser expressado de maneira alternativa para que as duas equações sejam agregadas. Para isso, toma-se a média ponderada das duas equações por $\pi_{b}$ e $\pi_{s}$ para obter:

$$
\hat{\lambda}_{t}=\hat{i}_{t}^{\text {avg }}-E_{t} \pi_{t+1}+E_{t} \hat{\lambda}_{t+1}
$$

em que $\hat{\lambda}_{t}=\pi_{b} \hat{\lambda}_{t}^{b}+\pi_{s} \hat{\lambda}_{t}^{s}$ é a média (em log) da utilidade marginal da renda, e a taxa de jutos média relevante para tomadores e poupadores pode ser expressa como:

$$
\hat{i}_{t}^{a v g}=\pi_{b} \hat{i}_{t}^{b}+\pi_{s} \hat{i}_{t}^{d}
$$

A ineficiência resultante do processo de intermediação pode ser obtida subtraindo (3) de (2). Assim, se define $\hat{\Omega}_{t}=\hat{\lambda}_{t}^{b}-\hat{\lambda}_{t}^{s}$ e $\hat{\omega}_{t}$ como o spread entre a taxa de juros recebida pelos poupadores e a paga pelos tomadores de empréstimo:

$$
\hat{\Omega}_{t}=\hat{\omega}_{t}+\delta E_{t} \hat{\Omega}_{t}
$$

As Equações (4) e (6) são equivalentes às Equações (2) e (3) originadas no problema dos consumidores. Contudo, elas destacam que a utilidade marginal da renda, assim como nos modelos tradicionais, está relacionada com a trajetória esperada da taxa de juros e que a dispersão da utilidade marginal da renda de cada tipo de agente depende apenas do spread $\hat{\omega}_{t}$.

Voltando às condições de primeira ordem, segue-se que todas as famílias de um determinado tipo também devem escolher o mesmo consumo em qualquer período, e, assumindo uma escolha anterior para o consumo por 
parte das famílias de cada tipo, esses níveis de consumo devem satisfazer $\lambda_{t}^{b}=u^{b^{\prime}}\left(c_{t}^{b}\right)$ e $\lambda_{t}^{s}=u^{s^{\prime}}\left(c_{t}^{s}\right)$. Essas equações podem ser invertidas para que se obtenham as funções de demanda,

$$
c_{t}^{b}=c^{b^{\prime}}\left(\lambda_{t}^{b}, \xi_{t}\right), \quad c_{t}^{s}=c^{s^{\prime}}\left(\lambda_{t}^{s}, \xi_{t}\right)
$$

A condição de market-clearing mostra que o dispêndio agregado da economia deve ser a soma do consumo das famílias e do governo. Portanto, a equação de fechamento da economia pelo lado da demanda assume a seguinte forma:

$$
Y_{t}=\int c_{t}(i) d_{i}+G_{t}+\Xi_{t}\left(b_{t}\right)
$$

A parcela $\Xi_{t}\left(b_{t}\right)$ refere-se aos recursos utilizados pelo setor de intermediação financeira, ou custo de operação dos intermediários financeiros, em que $b_{t}$ são os empréstimos reais totais da instituição financeira ${ }^{1}$. A forma funcional por Cúrdia \& Woodford (2010) para $E_{t}\left(b_{t}\right)$ é $\tilde{\Xi}_{t} b_{t}^{\eta}$. Os autores realizam simulações com diferentes valores para o parâmetro $\eta$. No caso em que $\eta=1$, obtêm-se uma tecnologia linear para os intermediários, de forma que aumentos no nível de crédito levam ao crescimento proporcional nos custos de intermediação. Já quando $\eta>1$, o aumento no nível de crédito leva a um aumento mais do que proporcional nos custos de intermediação. A expressão (14), que será apresentada adiante, mostra que o custo de intermediação é um dos elementos que compõem o spread no mercado de crédito.

Substituindo (7) em (8) obtém-se a equação de equilíbrio para a demanda agregada que relaciona as utilidades marginais da renda com o crédito da economia:

$$
Y_{t}=\pi_{b} c^{b}\left(\lambda_{t}^{b} ; \xi_{t}\right)+\pi_{s} c^{s}\left(\lambda_{t}^{s} ; \xi_{t}\right)+G_{t}+E_{t}(b)
$$

A representação em formato log-linear considera que o choque exógeno sobre as preferências é uma média ponderada na taxa de impaciência de ambos os agentes e está representado por $\bar{c}_{t}$. Além disso, na sua versão em estado estacionário, as variáveis foram definidas como $\hat{Y}_{t}=\log \left(Y_{t} / \hat{Y}\right), \hat{G}=$ $\left(G_{t}-\bar{G}\right) / \bar{Y}$ e $\hat{\Xi}_{t}=\left(E_{t}-\bar{\Xi}\right) / \bar{Y}$. Portanto, a representação da demanda agregada $\log$-linearizada possui a forma:

$$
\hat{Y}_{t}=s_{c} \bar{c}_{t}-\bar{\sigma}\left(\bar{\lambda}_{t}+s_{\Omega} \hat{\Omega}_{t}\right)+\hat{G}_{t}+\hat{\Xi}_{t}
$$

O coeficiente $\hat{\sigma}$ mede a sensibilidade da decisão de consumo das famílias a variações na utilidade marginal da renda. Essa relação também pode ser interpretada como a sensibilidade do consumidor em relação à taxa de juros. Vale destacar que ô é uma média ponderada dos dois tipos de famílias:

$$
\bar{\sigma}=\pi_{b} s_{b} \sigma_{b}+\pi_{s} s_{s} \sigma_{s}>0
$$

em que $\sigma_{\tau}$ é a elasticidade substituição intertemporal do consumo de cada agente e $s_{\tau}=\bar{c}_{t} / \bar{Y}$ é a participação do consumo de cada agente no consumo agregado em estado estacionário. O coeficiente $s_{\Omega}$ representa o grau no qual a demanda agregada é afetada pela heterogeneidade na utilidade marginal dos

\footnotetext{
${ }^{1}$ Em que $\Xi_{t}(0)=0, \Xi_{t}(b) \geq 0, \Xi_{t}^{\prime}(b) \geq 0$ e $\Xi_{t}^{\prime \prime}(b) \geq 0$ para todo $b \geq 0$.
} 
consumidores. Ele depende, fundamentalmente, da diferença entre elasticidade do consumo em relação à taxa de juros dos tomadores e dos poupadores $^{2}$.

As Equações (4) e (10) combinadas dão forma a uma relação IS intertemporal:

$$
\hat{Y}_{t}=E_{t} \hat{Y}_{t+1}-\bar{\sigma}\left(\hat{i}_{t}^{a v g}-E_{t} \pi_{t+1}\right)-E_{t}\left[\Delta g_{t+1}+\Delta \hat{\Xi}_{t+1}-\bar{\sigma} s_{\Omega} \Delta \hat{\Omega}_{t+1}\right]
$$

em que $g_{t}$ agrega as perturbações exógenas no dispêndio das famílias e do governo e $\Delta$ indica a primeira diferença das variáveis, conforme detalhado em Woodford \& Walsh (2003).

Mesmo havendo duas taxas de juros na economia, a política monetária poderá ser conduzida por uma taxa apenas. Utilizando a mesma abordagem do modelo de Goodfriend \& McCallum (2007), considera-se que o spread de equilíbrio depende da tecnologia dos intermediários. Supondo que o setor bancário atua em um mercado com competição perfeita, o spread em equilíbrio é dado por $\omega_{t}=\Xi_{t}^{\prime}(b)$. Essa suposição tem uma implicação forte para o modelo. Não há uma explicação comportamental (microfundamentada) para o spread entre as taxas de juros disponíveis aos poupadores e tomadores. Isso significa que não é possível avaliar os possíveis efeitos da política monetária sobre a eficiência do setor bancário ${ }^{3}$. Entretanto, será possível considerar as consequências na atuação da política monetária na presença de spread.

As taxas de juros na economia devem respeitar a seguinte relação de equilíbrio:

$$
\hat{i}_{t}^{b}=\hat{i}_{t}^{d}+\hat{w}_{t}
$$

em que $\hat{\omega}_{t}=\log \left[\left(1+\omega_{t}\right) /(1+\bar{\omega})\right]$. Além disso, há uma fonte de perturbação exógena para o spread no estado estacionário, que está associado ao aumento da utilização dos recursos da economia pelas instituições financeiras. Para tanto, assume-se que o spread de equilíbtio é dado por:

$$
1+\omega_{t}=\mu_{t}^{b}(b)\left(1+\Xi_{t}^{\prime}(b)\right)
$$

em que $\mu_{t} \geq 1$ é o mark-up do setor financeiro que é tomado como exógeno e variante no tempo. Entretanto, Cúrdia \& Woodford (2009) não interpretam $\mu_{t}^{b}$ apenas como uma forma de poder de mercado dos intermediários financeiros, mas, por exemplo, como uma forma de modelar o prêmio de risco que varia no tempo. A origem desse movimento pode ser o alto volume de crédito já concedido, que impõe mais riscos para a alavancagem das famílias ou o aumento de tomadores fraudulentos e inadimplentes na economia.

Portanto, a versão log-linear da equação de movimento do spread da taxa de juros (14) pode ser expressa como:

$$
\hat{\omega}_{t}=\omega_{b} \hat{b}_{t}+\omega_{\Xi} \hat{\Xi}_{t}+\omega_{\chi} \hat{\chi}_{t}
$$

A Equação (15) mostra que o spread da taxa de juros em estado estacionário depende do volume de endividamento privado, dado por $\hat{b}_{t}=\log \left(\frac{b_{t}}{\bar{b}}\right)$, e do custo dos intermediários financeiros $\left(\hat{E}_{t}\right)$. Além disso, o spread também

\footnotetext{
${ }^{2} \mathrm{O}$ coeficiente possui a seguinte forma: $s_{\Omega}=\pi_{b} \pi_{s} \frac{s_{b} \sigma_{b}-s_{s} \sigma_{b}}{\tilde{\omega}}$.

${ }^{3}$ Gertler \& Karadi (2011) é um exemplo de trabalho que busca microfundamentar os intermediários financeiros.
} 
é determinado por choques financeiros exógenos $\left(\hat{\chi}_{t}\right)$ que podem ser entendidos como variações no prêmio de risco, banking mark-ups ou aumento da inadimplência dos tomadores de empréstimo.

Combinando as Equações (13) em (5) é possível entender como a taxa média e a taxa básica de juros se relacionam com o spread em equilíbrio:

$$
\hat{i}_{t}^{a v g}=\hat{i}_{t}^{d}+\pi_{b} \hat{\omega}_{t}
$$

O fechamento da parte da demanda do modelo depende de uma relação entre o endividamento e as demais variáveis. A Equação (17) descreve o movimento da dívida real das famílias em estado estacionário como uma função do seu nível passado, dos choques exógenos no mercado financeiro que afetam o spread da taxa de juros, da evolução da taxa básica de juros da economia em relação à taxa de inflação, da evolução da dívida real do governo e das demais variáveis agregadas que determinam o nível de dispêndio e renda relativa de cada tipo de família:

$$
\begin{array}{r}
\hat{b}_{t}=\rho_{r}\left(\hat{i}_{t-1}^{d}-\pi_{t}\right)+\rho_{Y} \hat{Y}_{t}+\rho_{\Sigma} \hat{\Sigma}_{t}+\rho_{\omega} \hat{\omega}_{t}+\rho_{b}\left(\hat{b}_{t-1}-\hat{\omega}_{t-1}\right)+ \\
\rho_{\epsilon}\left[\pi_{b}\left(1-\pi_{b}\right) s_{c} \bar{c}_{t}+s_{\Sigma} \bar{\sigma}^{-1}\left(g_{t}+\hat{\Xi}_{t}\right)\right]-\pi_{b} \rho_{\epsilon}\left[\hat{b}_{t}^{g}-\delta\left(1+\bar{r}^{d}\right) \hat{b}_{t-1}^{g}\right]
\end{array}
$$

Os parâmetros $\rho^{\prime}$ s e $B^{\prime} s$ foram adotados para a simplificação de relações agregadas de parâmetros já descritos do modelo. A definição de cada um está no Apêndice 6.

Cúrdia \& Woodford (2010) demonstram que na presença de fricções financeiras a equivalência Ricardiana não se verifica nesse modelo. A equação de movimento (17) tem como consequência que, na ausência de alterações nas trajetórias das demais variáveis endógenas, uma mudança na trajetória de $\hat{b}_{t}^{g}$ representará uma alteração na trajetória de $\hat{b}_{t}$. Em outras palavras, na ausência de elementos que elevem a trajetória da dívida privada, haverá um efeito crowding-out da dívida pública em relação à privada. Nesse caso, a alteração no endividamento privado terá consequências sobre a determinação da demanda agregada, seja pela mudança no spread e/ou pelos recursos utilizados na intermediação financeira.

Portanto, além da equação de movimento da dívida, a parte da demanda é composta da equação IS intertemporal do modelo Novo Keynesiano (12) e da Equação (16), que relaciona a taxa de juros média com a taxa de juros básica da economia. Completa esse bloco a Equação (6), que relaciona a demanda agregada e as equações que expressam a relação entre a utilidade marginal da renda de cada família e a taxa de retorno real esperada da decisão entre poupança e consumo.

A parte da oferta agregada é similar aos modelos tradicionais Gertler \& Karadi (2011), Woodford \& Walsh (2003), Benigno \& Woodford (2005), em que a relação entre o produto, inflação e expectativas são representadas numa curva de Phillips Novo Keynesiana.

$$
\pi_{t}=\beta E_{t} \pi_{t+1}+\kappa\left(\hat{Y}_{t}-\hat{Y}_{t}^{n}\right)+\xi u_{t}-\xi \bar{\sigma}^{-1} \hat{\Xi}_{t}+\xi\left(s_{\Sigma}+\pi_{b}-\gamma_{b}\right) \hat{\Sigma}_{t}
$$

com inclinação dada por $\kappa=\epsilon\left(\omega_{y}+\bar{\sigma}^{-1}\right)>0$, em que $\epsilon=\frac{1-\alpha}{\alpha} \frac{1-\alpha \beta}{1+\omega_{y} \theta}$. O parâmetro $0<\alpha<1$ é a fração dos preços que ficam inalterados do período atual para o próximo, $\theta$ representa a elasticidade substituição consumo entre os diferentes tipos de bens e $\omega_{y}$ é o mark-up desejado para os salários. 
Os três primeiros elementos de (18) são equivalentes aos obtidos num modelo DSGE tradicional. No caso do modelo com fricções financeiras há o acréscimo de dois cost-push choques decorrentes da parte financeira do modelo, cujos efeitos imediatos são a elevação na taxa de inflação.

O termo para a taxa de crescimento do produto natural, $\hat{Y}_{t}^{n}$, agrega, por meio de uma combinação linear, as perturbações exógenas $\bar{c}_{t}, \bar{G}_{t}$ e $z_{t}$. Esses choques correspondem às fontes de variação no nível de produto com preços flexíveis, que na ausência de fricções financeiras correspondem às variações no nível de eficiência da produção. Complementarmente, o termo $u_{t}$ agrega as variáveis exógenas que podem representar pressões sobre os custos, ou seja são fontes de variação no produto de equilíbrio que não correspondem a qualquer mudança no nível de produção eficiente.

O Banco Central pode seguir uma Regra de Taylor tradicional para $\hat{i}_{t}^{d}$, na forma de (19) em que a Equação (16) relaciona a taxa da política monetária com a taxa média da economia:

$$
\hat{i}_{t}^{d}=\phi_{m} \hat{i}_{t-1}^{d}+\left(1-\phi_{m}\right)\left(\phi_{\pi} \pi_{t}+\phi_{y} \hat{Y}_{t}\right)+\epsilon_{t}^{m}
$$

Cúrdia \& Woodford (2010) mostram que a determinação da inflação e do produto ocorre da mesma forma do que no modelo tradicional, independentemente do grau das friç̧ões financeiras ou da sua variabilidade. Além disso, na modelagem de Goodfriend \& McCallum (2007) para o spread, se torna possível que mesmo com duas taxas de juros com papel distinto, a política monetária seja conduzida por meio da taxa livre de risco (taxa dos depósitos das famílias), $i_{t}^{d}$.

O modelo apresentado mantém as mesmas relações que um modelo DSGE tradicional. Porém, existem duas principais diferenças. A primeira delas estabelece a existência de duas taxas de juros que afetam a demanda agregada (ambas impactam com o mesmo sinal) por meio das diferentes decisões de consumo de cada tipo de agente. A segunda diferença em relação ao modelo tradicional estabelece que os recursos utilizados pelos intermediários financeiros também impactam na demanda agregada.

No caso dos bancos não utilizarem nenhum recurso, $\left(\Xi_{t}(b)=0\right)$, a dinâmica do modelo será semelhante à de um modelo tradicional sem fricções financeiras. Da mesma forma, o modelo tradicional de Woodford \& Walsh (2003) pode ser entendido como um caso especial desse modelo com fricções financeiras para quando $u^{b}(c, \xi)=u^{s}(c, \xi)$ e $\xi_{t}(0)$. Nesse caso, $i_{t}^{b}=i_{t}^{d}$ vale para todo o $t$ e o que implica que $\lambda_{t}^{b}=\lambda_{t}^{s}$. Por consequência o spread será nulo, ou seja, $\omega_{t}(b)=0$. Assim, será possível estimar o modelo para a economia brasileira com e sem friç̧ões financeiras.

Em resumo, o modelo completo possui sete equações principais: a) medida da ineficiência da intermediação financeira (6), b) curva IS com fricções financeiras (12), c) equação do spread de crédito (15), d) média das taxas de juros que são relevantes para os poupadores e investidores (16), e) equação da dinâmica do endividamento privado (17), f) curva de Phillips com fricções financeiras (18), e g) regra de política monetária (19).

As perturbações exógenas são compostas por seis variáveis independentes e identicamente distribuídas (i.i.d.). São elas: choque nos gastos do governo $\left(\epsilon_{t}^{g}\right)$, choque na curva de Phillips $\left(\epsilon_{t}^{u}\right)$, choques financeiros exógenos $\left(\epsilon_{t}^{\chi}\right)$, choque na função de produção dos intermediários $\left(\epsilon_{t}^{\Xi}\right)$, choque no produto natural (tecnológico) $\left(\epsilon_{t}^{Z}\right)$, choque de juros na regra de política monetária $\left(\epsilon_{t}^{m}\right)$. 
Os termos que representam choques exógenos no dispêndio são agregados na variável $g_{t}$ e perfil de consumo das famílias deve obedecer o comportamento do consumo agregado, para tanto o dispêndio total é uma combinação linear dos dois tipos de consumidores:

$$
\begin{gathered}
s_{c} \bar{c}_{t}=\pi_{b} s_{b}+\left(1-\pi_{b}\right) s_{s} \\
g_{t}=\epsilon_{t}^{g}+s_{c} \bar{c}_{t}
\end{gathered}
$$

Pelo lado da oferta os choques que afetam o produto natural foram agregados na forma:

$$
\hat{Y}_{t}^{n}=\left(\omega_{y}+\bar{\sigma}^{-1}\right)^{-1}\left[\bar{\sigma}^{-1} g_{t}+\left(1+\omega_{y}\right) z_{t}\right]
$$

Os demais choques se desenvolvem no tempo como um processo $\operatorname{AR}(1)$ :

$$
\begin{gathered}
u_{t}=\rho_{u} u_{t}+\epsilon_{t}^{u} \\
Z_{t}=\rho_{Z} Z_{t-1}+\epsilon_{t}^{Z} \\
b_{t}^{g}=\rho_{g} b_{t-1}^{g}+\epsilon_{t}^{g} \\
\tilde{\Xi}_{t}=\rho_{\Xi} \Xi_{t-1}+\epsilon_{t}^{\Xi} \\
\chi_{t}=\rho_{\chi} \chi_{t-1}+\epsilon_{t}^{\chi}
\end{gathered}
$$

As relações estruturais do modelo foram apresentadas nesta seção, já estavam na sua forma log-linearizadas em torno dos valores de estado estacionário. A solução desse conjunto de equações lineares resulta na aproximação linear das variáveis endógenas em função dos diversos choques exógenos, para quando esses distúrbios são pequenos o suficiente.

\section{Dados e estimação}

O estudo econométrico para a economia brasileira abrange o período do terceiro trimestre de 2000 até o terceiro trimestre de 2014. Esse período é posterior à adoção do sistema de metas de inflação e da flutuação cambial, o que torna as estimações mais confiáveis, uma vez que não houve ruptura institucional nos mecanismos de condução da política macroeconômica.

A base de dados para a estimação do modelo contém sete séries econômicas. As observações para o PIB $\left(Y_{t}\right)$, Despesa com consumo das famílias $\left(c_{t}\right)$, Saldo das operações de crédito para as famílias $\left(b_{t}\right)$ e Dívida bruta do governo geral $\left(b_{t}^{g}\right)$ foram dessazonalizadas e tratadas como o log-diferença em relação à sua tendência de longo prazo, calculada por meio do filtro HP $(\lambda=1600)$.

A série escolhida para a taxa de inflação $\left(\pi_{t}\right)$ foi Índice de Preços ao Consumidor Amplo mensal. Os dados foram dessazonalizados pelo método X-12 ARIMA, transformados para a periodicidade trimestral e diferenciados em relação à média do período. As séries para a taxa de juros referência para a 
política monetária - Taxa Selic over $\left(i_{t}^{d}\right)$, bem como o spread médio das operações de crédito para pessoas físicas $\left(\omega_{t}\right)$ foram diferenciadas em relação à sua tendência de longo prazo ${ }^{4}$.

As equações que compõem as relações de equilíbrio do modelo foram apresentadas na seção anterior já na forma log-linearizada em torno do valor de estado estacionário. Sem qualquer perda de generalidade, $\bar{Y}=1$ e $\psi=1$ foram calibrados para que a inflação no estado estacionário seja zero. Os demais valores das variáveis em estado estacionário e parâmetros calibrados estão relacionados na Tabela 1. Os parâmetros calibrados, juntamente com aqueles a serem estimados, são suficientes para obter o equilíbrio do modelo por meio das equações do modelo, apresentadas acima, e das relações entre os parâmetros contidos no Apêndice 6.

Tabela 1: Valores no estado estacionário

\begin{tabular}{|c|c|c|c|}
\hline Parâmetro & Valor & Descrição & Fonte \\
\hline$b_{Y}$ & 1,3 & $\begin{array}{l}\text { Endividamento total da economia como } \\
\text { percentual do PIB }\end{array}$ & Banco Central do Brasil \\
\hline$\alpha$ & 0,74 & $\begin{array}{l}\text { Preços inalterados para o próximo pe- } \\
\text { ríodo }\end{array}$ & Castro et al. (2011) \\
\hline$v$ & 0,49 & Elasticidade substituição do trabalho & Castro et al. (2011) \\
\hline $\bar{\mu}_{\omega}$ & 0,25 & $\begin{array}{l}\text { Percentual dos trabalhadores que remar- } \\
\text { cam salários a cada período }\end{array}$ & Castro et al. (2011) \\
\hline $\bar{\tau}$ & 0,35 & $\begin{array}{l}\text { Participação dos impostos no PIB em es- } \\
\text { tado estacionário }\end{array}$ & $\begin{array}{l}\text { Carga tributária total }-\mathrm{Se}- \\
\text { cretaria da Receita Federal }\end{array}$ \\
\hline $\bar{\omega}$ & 0,30 & $\begin{array}{l}\text { Taxa média do spread (ao ano) para os } \\
\text { empréstimos totais para pessoas físicas } \\
\text { em estado estacionário }\end{array}$ & Banco Central do Brasil \\
\hline$\theta$ & 11 & $\begin{array}{l}\text { Elasticidade substituição entre os bens } \\
\text { de consumo }\end{array}$ & Castro et al. (2011) \\
\hline
\end{tabular}

Fonte: Elaborado pelos autores.

Os parâmetros fundamentais do modelo foram estimados por métodos Bayesianos. Nessa metodologia são escolhidas distribuições a priori para os parâmetros, os quais são utilizados para a determinação da função de verossimilhança.

A construção das distribuições a posteriori dos parâmetros foi realizada utilizando o algoritmo de Metropolis-Hastings, que utiliza o método de MCMC para a construção das distribuições posteriori. Para que a convergência fosse atingida, segundo o teste de diagnóstico proposto por Brooks \& Gelman (2012), foram realizadas 1 milhão de simulações em 4 cadeias de Markov ${ }^{5}$. Os trabalhos de An \& Schorfheide (2007) e DeJong \& Dave (2011) realizam uma

\footnotetext{
${ }^{4}$ A série do saldo das operações de crédito para famílias sofreu alteração metodológica pelo Banco Central do Brasil a partir de 2011. A diferença entre as séries novas e antigas ocorre em seu nível, mas mantém um coeficiente de correlação de 0,997 no período de 70 meses em que as duas séries coexistem. Assim, visto que o modelo tem o steady state centrado em zero, o nível da série não é uma informação essencial para todo o período. Dessa forma, a série para o período completo a partir das variações das duas séries de dados.

${ }^{5}$ As rotinas para a estimação foram implementadas utilizando o Dynare Versão 4, programa desenvolvido por Stéphane et al. (2011) que foi implementado utilizando o Matlab 2013a.
} 
abordagem detalhada da metodologia de estimação Bayesiana para modelos DSGE.

O principal desafio na estimação do modelo foi identificar os parâmetros de participação do consumo na renda dos dois tipos de famílias $\left(s_{b}\right.$ e $\left.s_{s}\right)$, bem como as suas elasticidades substituição intertemporais no consumo $\left(\sigma_{b}\right.$ e $\left.\sigma_{s}\right)$. A estimação de todos os parâmetros do modelo resultou em colinearidade entre esses parâmetros, conforme o teste de Iskrev (2010). Esse problema pode ser verificado por meio da Equação (20), em que se observa que o consumo agregado é uma combinação linear dos parâmetros para os tipos de famílias.

Desse modo, optou-se por estimar a elasticidade agregada, tendo em vista que os valores da literatura servem de referência para a definição das médias das distribuições a priori, e a estimativa do parâmetro para as famílias tomadoras de crédito. Os valores dos parâmetros para as famílias poupadoras foram obtidos a partir desses dois e das variáveis de spread em estado estacionário.

A estimação do inverso da elasticidade substituição agregada possui resultados bem reportados na literatura, como em Castro et al. (2011)) e Vasconcelos \& Divino (2012), que obtiveram estimativas entre 1,1 e 1,3. Assim, foram escolhidos valores iniciais para a elasticidade substituição de cada família ( $\sigma_{b}$ $=2,80$ e $\sigma_{s}=1,30$ ) que proporcionam uma elasticidade substituição agregada de 1,30 .

Para os parâmetros referente ao perfil e comportamento das famílias utilizou-se como média da distribuição a priori os valores do trabalho de Cúrdia \& Woodford (2009), devido à falta de informação para a economia brasileira que se adeque à proposta desse modelo. Portanto, considerou-se uma participação igual para cada tipo de família $\left(\pi_{b}=0,5\right)$. Quanto à proporção de consumo de cada tipo de família no PIB $\left(s_{b}=0,72\right.$ e $\left.s_{s}=0,50\right)$, os valores iniciais foram configurados para que se obtenha uma relação consumo/PIB de 0,61 , valor observado nos dados para a economia brasileira na média do período entre o segundo trimestre de 2000 e o segundo trimestre de 2014.

A escolha das distribuições a priori tem papel fundamental para o desempenho da estimação. A distribuição Beta foi utilizada com a priori para os parâmetros que assumem valores no intervalo $[0,1]$, para aqueles parâmetros com valores estritamente positivos foi escolhida a distribuição Gamma e para a estimativa dos desvios padrões dos choques aleatórios utilizou-se a distribuição Gamma Inversa com variância infinita. O modelo segue a linha básica de Woodford \& Walsh (2003) com origens no conceito de economia wickselliana e utiliza o conceito de taxa de juros natural. Note que se $\bar{\omega}=0$, então a taxa de juros em estado estacionário corresponde a $1+\bar{r}^{d}=\beta^{-1}$. Portanto, utilizou-se as relações de estado estacionário para calibrar $\beta$, dados os valores assumidos para $\delta, \pi_{b}, \bar{\omega}$ e $\bar{i}^{d}$, no modelo de fricções financeiras.

Com relação à identificação do modelo, os testes apontaram colinearidade entre os parâmetros $\sigma_{b}$ e $s_{b}$ resultando em indeterminação da solução do modelo para $3,2 \%$ do suporte das distribuições a priori. Esse resultado não impossibilitou o diagnóstico de identificação de Iskrev (2010) que sugeriu a relevância desses parâmetros para o modelo.

No geral as estimações conseguiram apontar comportamentos (parâmetros) distintos entre os agentes da economia. Tomando os resultados das estimações para $s_{b}, \sigma_{b}$ e $\pi_{b}$ e considerando uma participação da despesa de consumo agregado das famílias no PIB de $62 \%$, é possível obter os parâmetros para as famílias poupadoras, $s_{b}=0,48$ e $\sigma_{s}=1,21$. 
Tabela 2: Distribuição a priori e posteriori dos parâmetros

\begin{tabular}{lcccccc}
\hline \multirow{2}{*}{ Parâmetro } & Densidade & \multicolumn{2}{c}{ Priori } & \multicolumn{2}{c}{ Posteriori } & \multirow{2}{*}{ Muporte } \\
& & Média & D. P. & Média & Conf. 90\% & \\
\hline$\pi_{b}$ & Gamma & 0,5000 & 0,1000 & 0,4700 & {$[0,3965 ; 0,5412]$} & $\mathbb{R}^{+}$ \\
$s_{b}$ & Beta & 0,7800 & 0,1000 & 0,7820 & {$[0,7311 ; 0,8269]$} & {$[0,1]$} \\
$\sigma_{b}$ & Beta & 2,8000 & 0,5000 & 2,7100 & {$[1,9336 ; 3,4349]$} & {$[0,1]$} \\
$\bar{\sigma}$ & Beta & 1,3000 & 0,1000 & 1,1800 & {$[1,0499 ; 1,3053]$} & {$[0,1]$} \\
$\delta$ & Beta & 0,9750 & 0,1000 & 0,9740 & {$[0,9660 ; 0,9813]$} & {$[0,1]$} \\
$\eta$ & Gamma & 5,0000 & 1,0000 & 3,7200 & {$[2,7469 ; 4,6571]$} & $\mathbb{R}^{+}$ \\
$\phi_{\pi}$ & Gamma & 2,4300 & 0,1000 & 2,1800 & {$[2,0398 ; 2,3285]$} & $\mathbb{R}^{+}$ \\
$\phi_{y}$ & Gamma & 0,1600 & 0,1000 & 0,6500 & {$[0,5867 ; 0,7046]$} & $\mathbb{R}^{+}$ \\
$\phi_{m}$ & Beta & 0,7900 & 0,1000 & 0,8000 & {$[0,7844 ; 0,8174]$} & {$[0,1]$} \\
$\rho_{Z}$ & Beta & 0,5000 & 0,1000 & 0,6100 & {$[0,4845 ; 0,7434]$} & {$[0,1]$} \\
$\rho_{\Xi}$ & Beta & 0,5000 & 0,1000 & 0,9000 & {$[0,8654 ; 0,9500]$} & {$[0,1]$} \\
$\rho_{b g}^{g}$ & Beta & 0,5000 & 0,1000 & 0,6200 & {$[0,5054 ; 0,7339]$} & {$[0,1]$} \\
$\rho_{u}^{u}$ & Beta & 0,5000 & 0,1000 & 0,5200 & {$[0,3549 ; 0,6782]$} & {$[0,1]$} \\
$\epsilon_{t}^{u}$ & Inv. Gamma & 0,0100 & Inf. & 0,0047 & {$[0,0011 ; 0,0087]$} & {$[0,1]$} \\
$\epsilon_{t}^{Z}$ & Inv. Gamma & 0,0100 & Inf. & 0,9829 & {$[0,6645 ; 1,2924]$} & {$[0,1]$} \\
$\epsilon_{t}^{m}$ & Inv. Gamma & 0,0100 & Inf. & 0,0165 & {$[0,0135 ; 0,0194]$} & $\mathbb{R}^{+}$ \\
$\epsilon_{t}^{b}$ & Inv. Gamma. & 0,0100 & Inf. & 0,0568 & {$[0,0463 ; 0,0671]$} & $\mathbb{R}^{+}$ \\
$\epsilon_{t}^{g}$ & Inv. Gamma & 0,0100 & Inf. & 0,0388 & {$[0,0321 ; 0,0452]$} & $\mathbb{R}^{+}$ \\
$\epsilon_{t}^{\chi}$ & Inv. Gamma & 0,0100 & Inf. & 0,0215 & {$[0,0181 ; 0,0248]$} & $\mathbb{R}^{+}$ \\
$\epsilon_{t}^{b}$ & Inv. Gamma & 0,0000 & Inf. & 0,0019 & {$[0,0013 ; 0,0024]$} & $\mathbb{R}^{+}$ \\
$\epsilon_{t}^{\Xi}$ & Inv. Gamma & 0,0100 & Inf. & 0,0047 & {$[0,0011 ; 0,0087]$} & $\mathbb{R}^{+}$ \\
\hline
\end{tabular}

Fonte: Elaborado pelo autor.

Na curva de Phillips, a resposta da inflação corrente às mudanças no hiato do produto é de $\kappa=0,038$, que é um valor próximo ao encontrado na literatura aplicada à economia brasileira. O parâmetro para a probabilidade média com que o agente permanece com um mesmo perfil $(\delta=0,974)$ indica que consumidor altera o seu perfil a cada 10 anos, ou seja, o agente permanece como tomador de crédito por 10 anos em média.

\section{Análises das estimações e simulações}

Para analisar como a inclusão do spread entre as taxas de juros altera o comportamento do modelo tradicional sem fricções financeiras, foram realizados diferentes tipos de choques exógenos. As variáveis de resposta foram o produto $\left(Y_{t}\right)$, a taxa de inflação $\left(\pi_{t}\right)$, a taxa de juros que os emprestadores recebem ao poupar $\left(i_{t}^{d}\right)$, o spread entre as taxas de juros $\left(\omega_{t}\right)$ e o volume de crédito na economia $\left(b_{t}\right)$. Em todas as simulações desta e das próximas partes do trabalho os choques tiveram um fator de persistência de acordo com o resultado da estimação do modelo com fricções financeiras. A trajetória das variáveis é apresentada em termos de desvio percentual em relação ao valor de estado estacionário.

Em cada uma das simulações, o modelo com fricções financeiras estimado é contrastado com a versão sem fricções. O modelo sem fricções se assemelha ao de Woodford \& Walsh (2003), pois não há spread entre as taxas de juros $\left(\omega_{t}(b)=0\right)$, nem entre os custos de transação decorrentes da intermediação financeira $\left(\Xi_{t}(b)=0\right)$. Porém, foi mantida a heterogeneidade das preferências dos consumidores e a equação para o crédito agregado. Destaca-se que em ambos os casos a política monetária é conduzida com uma regra de política monetária com parâmetros idênticos. 
Figura 3: Resposta dos modelos ao choque de 1 desvio padrão na produtividade $\left(\epsilon_{t}^{Z}\right)$

Produto (Y)
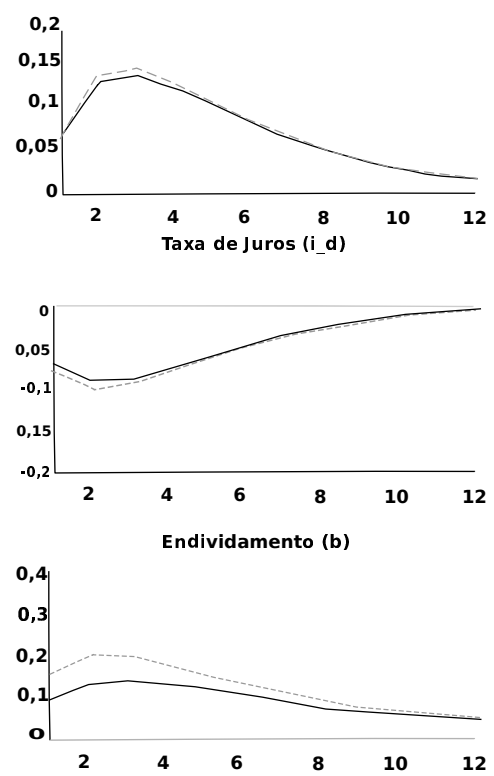

Fonte: Elaborado pelo autor.
Taxa de Inflação (pi)
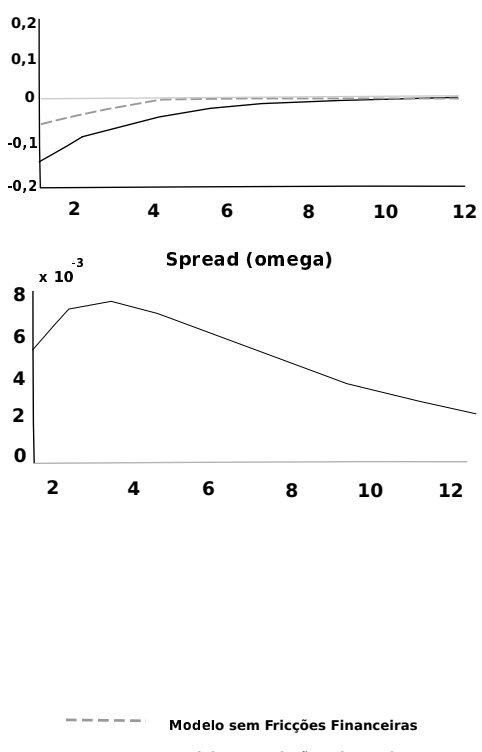

A Figura 3 mostra a resposta dos modelos a um choque de $1 \%$ na produtividade da economia. O choque produz nos dois modelos o resultado esperado pela literatura, qual seja, o aumento no produto e a redução na taxa de juros e na taxa de inflação. No modelo com fricções financeiras, o spread aumenta, o que resulta em efeitos contracionistas sobre a demanda agregada por meio da menor expansão no crédito agregado. Nesse caso, o produto cresce menos e a inflação desacelera mais do que no modelo sem friç̧ões financeiras.

A Figura 4 apresenta a resposta de um choque contracionista de 1 ponto percentual na taxa de juros. O principal efeito decorrente da variação endógena do spread no modelo com fricções financeiras ocorre nas respostas ao choque na taxa de juros. O crédito na economia é contraído em resposta ao aumento na taxa de juros, pois o spread entre a taxa dos tomadores e a taxa de juros base da economia aumenta. Como consequência do aumento no spread, há um efeito contracionista na demanda agregada e a desinflação é maior em resposta ao aumento na taxa de juros da política monetária do que no modelo sem fricções financeiras.

A Figura 5 mostra o comportamento de equilíbrio dos modelos em resposta a um choque nos dispêndios do governo. Vale destacar que um choque na demanda por consumo das famílias poupadoras (não mostrado) teria um efeito bastante semelhante. Esses choques se assemelham, pois proporcionam um efeito deslocamento (crowding-out) na despesa das famílias tomadoras de recursos (tipo $b$ ) - aqueles que tem seu consumo mais sensível à taxa de juros - o que reduz o volume de crédito de equilíbrio e o spread. O menor endividamento e a redução do spread têm efeitos sobre a taxa de juros básica da economia, resultando numa menor expansão da demanda agregada. Por conta desse efeito, há uma desinflação na economia, ao contrário do que ocorre no 
Figura 4: Resposta dos modelos ao choque de choque de 1 ponto percentual na taxa de juros do Banco Central $\left(\epsilon_{t}^{m}\right)$

Produto (Y)
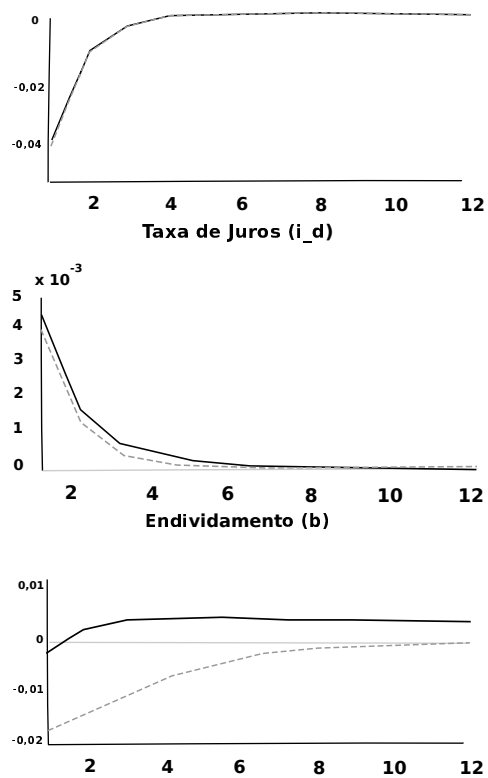

Fonte: Elaborado pelo autor.
Taxa de Inflação (pi)
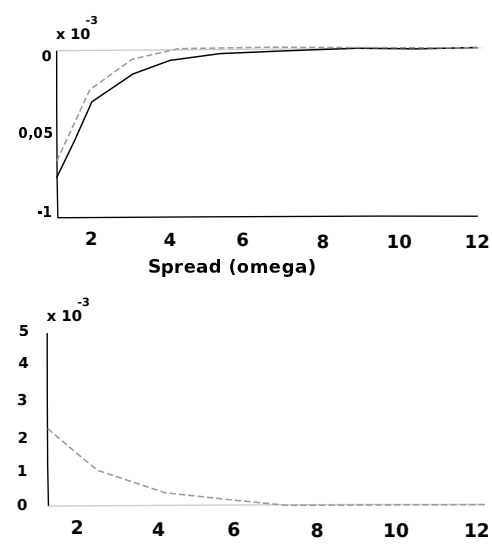

Modelo sem F. Financeiras

Figura 5: Resposta dos modelos ao choque de choque de $1 \mathrm{dp}$ no gasto público $\left(\epsilon_{t}^{g}\right)$

Produto (Y)
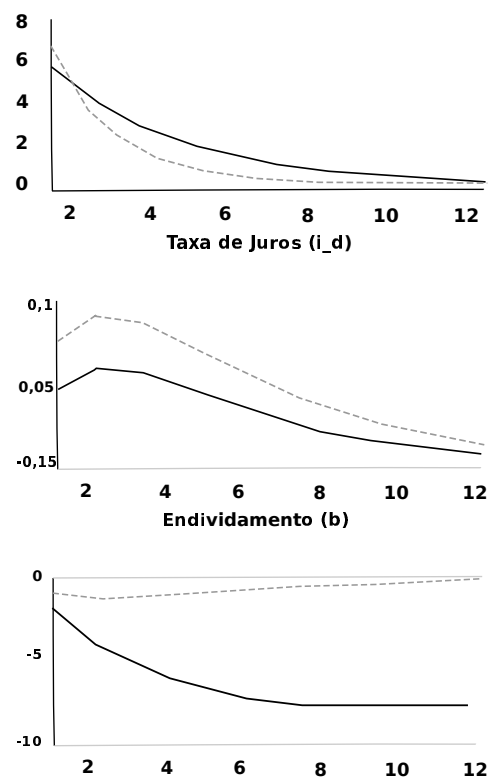

Fonte: Elaborado pelo autor.
Taxa de Inflação (pi)
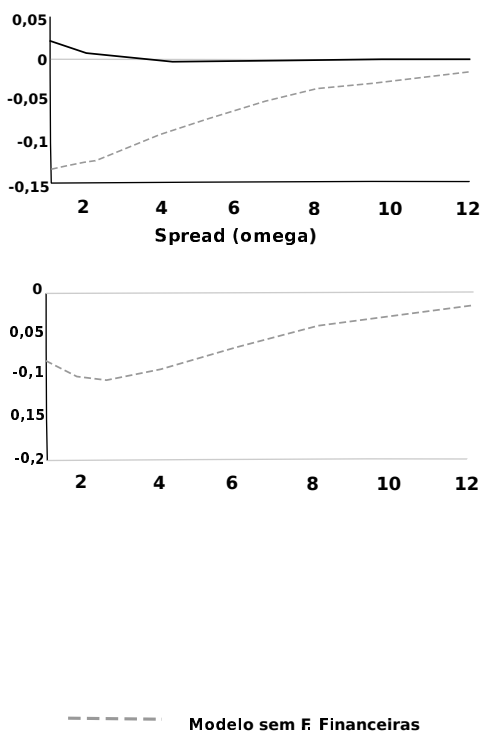

Modelo com F. Financeiras 
modelo sem fricções financeiras e o que está mais de acordo com a literatura.

Por fim, é analisado o comportamento dos modelos em resposta a um aumento de 1 desvio padrão no consumo dos agentes tomadores de crédito (tipo b). Nesse caso, observa-se que o crédito privado aumenta por conta da maior elasticidade-juros da demanda dos tomadores. Isso implica um pequeno aumento no spread, fazendo com que o choque seja menos expansivo do que aquele que seria verificado no caso de um choque no consumo dos poupadores ou mesmo no consumo do governo, conforme mostrado anteriormente. Os efeitos agregados das fricções financeiras são ainda menores no caso de um aumento uniforme na procura do consumo de ambos os tipos de famílias, uma vez que, nesse caso, os efeitos dos dois tipos de despesas no crédito de equilíbrio seriam parcialmente compensados entre si.

Figura 6: Respostas dos modelos ao choque de choque de 1 desvio padrão no consumo dos agentes do tipo $b$
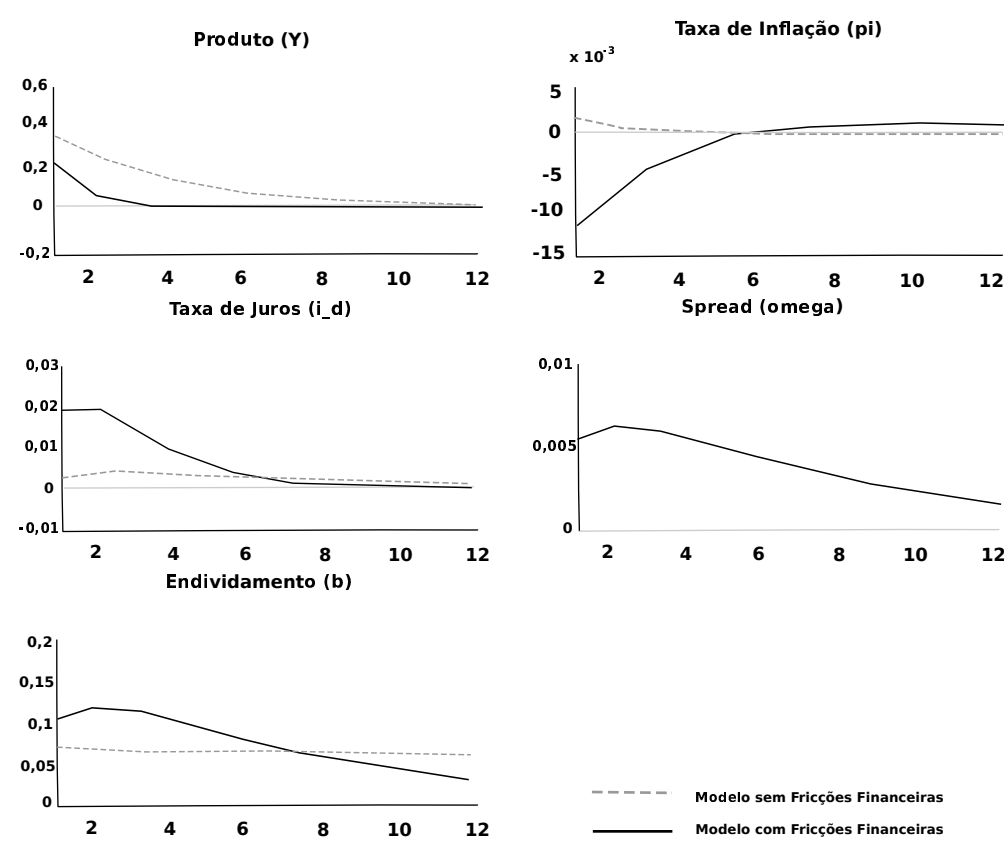

Fonte: Elaborado pelo autor.

As simulações mostraram que a inclusão de fricções financeiras não altera o comportamento esperado do modelo Novo Keynesiano diante dos choques tradicionais de política monetária, produtividade e demanda agregada. Porém, da mesma forma como o verificado no trabalho de Vega Filho (2013), a resposta da taxa de inflação a um choque nos gastos do governo foi diferente do esperado. O movimento aguardado para os preços, no caso de um aumento no dispêndio público, é de aumento na taxa de inflação. A desinflação observada decorre do menor endividamento em decorrência da queda no consumo das famílias tomadoras de crédito.

Quanto aos demais choques, a resposta das variáveis foi semelhante ao apresentado por Vega Filho (2013). Contudo, a magnitude e persistência dos choques foram bastante distintas, visto que o modelo estimado capturou a maior volatilidade dos dados da economia brasileira, elemento que não foi 
possível no trabalho de Vega Filho (2013) ao utilizar parâmetros do modelo calibrado por Cúrdia \& Woodford (2009) para a economia dos EUA.

A inclusão de fricções financeiras torna possível a realização de choques exógenos na intermediação financeira, que é representada por variações na função de custo de crédito, $\Xi_{t}(b)$, e no mark-up da intermediação, $\chi_{t}$. Na construção do modelo de Cúrdia \& Woodford (2010) esses choques são relevantes na determinação da produção agregada, inflação e taxa de juros que implicam na variação do spread na economia. Nas próximas seções será analisado o comportamento do modelo diante dessas perturbações sobre diferentes configurações da política monetária.

\subsection{Regras monetárias ótimas para o Banco Central considerando o spread para a taxa de juros}

Esta parte tem o objetivo de formular uma Regra Ótima de política monetária, que é obtida por meio da minimização intertemporal de uma função de perda linear quadrática, sujeita às equações dadas pela estrutura da economia que contempla a existência de spread das taxas de juros. Tendo em vista a inclusão de fricções financeiras, a função de perda do Banco Central deverá levar em conta essa característica.

Para a construção da Regra Ótima, supõe-se que o objetivo dos formuladores de política monetária seja maximizar a utilidade esperada ex ante das famílias. Como mostrado em Rotemberg \& Woodford (1997) e Benigno \& Woodford (2005) é possível, sob certas hipóteses, obter uma aproximação linear da política ótima, no caso de pequenas flutuações em torno do estado estacionário ótimo de longo prazo utilizando o método de aproximação linear quadrática. A minimização da função de perda linear quadrática é o equivalente a maximizar a função de bem-estar sujeita às restrições do modelo. Essa regra de política monetária poderá ser considerada uma aproximação linear da Regra Ótima.

Em termos estatísticos, o problema de minimização linear quadrática consiste na escolha de um subconjunto dos parâmetros que minimiza a (co)variância de um subconjunto específico de variáveis endógenas sujeito a uma lei de movimento linear decorrente das condições de primeira ordem do modelo.

Cúrdia \& Woodford (2009) derivam a função de perda para o problema apresentado neste trabalho. O processo para obter a função de perda consiste na aproximação de Taylor da função de utilidade em torno dos seus valores no estado estacionário com inflação zero e descartando os termos de ordem maior. Assim, chega-se na seguinte especificação para a função de perda do modelo de spread:

$$
L_{t}=\pi_{t}^{2}+\lambda_{y}\left(Y_{t}^{2}+\hat{Y}_{t}^{n}\right)^{2}+\lambda_{\Sigma} \hat{\Sigma}_{t}+\lambda_{\Xi} \Xi_{b t} \hat{b}_{t}
$$

Os fatores de ponderação $\lambda_{y}, \lambda_{\Sigma}, \lambda_{\Xi}>0$ são definidos a partir dos demais parâmetros do modelo e estão descritos no Apêndice Apêndice A. A maximização da utilidade média esperada é equivalente a minimização do valor esperado descontado da função de perda (29). Um dos pontos positivos dessa abordagem é que como a função é puramente quadrática, ela pode ser avaliada usando apenas a aproximação log-linear das variáveis endógenas em equilíbrio para uma dada política.

Vale destacar que os dois primeiros termos de (29) são semelhantes aos obtidos no modelo Novo Keynesiano tradicional sem fricções financeiras. Se ao 
invés de permitir que o spread entre as taxas de juros varie no tempo, se considere que não há variações endógenas nessas friç̧ões, ou seja, se $\omega_{t}, \Xi_{t}$ forem processos exógenos, independentes do endividamento das famílias, obtém-se uma caracterização da função de perda, similar ao do modelo sem fricções financeiras. Nesse caso, o último termo da expressão (29) será zero e o penúltimo termo será independente da função de política adotada, uma vez que a aproximação log-linear de (6) implica que se $\omega_{t}$ é um processo exógeno, $\Sigma_{t}$ também será. Portanto, é possível escrever a função de perda do Banco Central da forma tradicional do modelo Novo Keynesiano:

$$
L_{t}=\pi_{t}^{2}+\lambda_{y}\left(Y_{t}^{2}+\hat{Y}_{t}^{n}\right)^{2}
$$

Porém, mesmo considerando os choques sobre o setor financeiro como exógenos e zero em estado estacionário, o Banco Central, ao implementar a política ótima, ainda deverá monitorar o tamanho das variações do spread de crédito para o cumprimento das suas metas. É perceptível que o tamanho do spread importará para a política monetária por duas razões. As trajetórias da taxa de inflação e do hiato do produto consistentes com a função de perda dependem da evolução do spread, porque essa variável influencia a oferta agregada da economia, como mostra a especificação da curva de Phillips. Da mesma forma, o spread de crédito por causa de seus efeitos sobre a curva IS por conta da relação entre a taxa de juros da política monetária e taxa média de juros.

Para realizar a estimação da Regra Ótima é preciso definir as preferências da autoridade monetária para a taxa de inflação, a taxa de juros nominal e o produto. Neste trabalho, optou-se por calibrar a matriz de ponderações para a minimização da função de perda (29) por meio da regra de política monetária (19) com base no trabalho de Aragón \& Portugal (2009). Dessa forma, para a estabilização da inflação foi dado um peso de 0,727 , já o peso da estabilização do produto foi 0,073 e o peso da estabilização da taxa de juros nominal no valor de 0,2 .

O resultado da minimização da função de perda do Banco Central, com o modelo calibrado com os parâmetros estimados, obteve os seguintes parâmetros para a regra de política monetária ótima: $\phi_{\pi}=2,42, \phi_{y}=0,48$ e $\phi_{m}$ $=0,75$. Em comparação com os parâmetros estimados, a Regra Ótima preconiza uma maior agressividade no combate dos desvios da taxa de inflação em relação ao estado estacionário do que o obtido por meio da estimação da seção anterior. Em relação aos resultados de Castro et al. (2011), observa-se estimativas próximas para os parâmetros relacionados à taxa de inflação e à suavização dos movimentos na taxa de juros nominal. Em compensação, a Regra Ótima sugere um comportamento mais agressivo no combate aos desvios do produto.

Uma das principais utilidades de derivar uma Regra Ótima é avaliar em qual grau regras de política monetária alternativas podem atingir resultados semelhantes. Para isso, nos exercícios de simulação das próximas a Regra Ótima não será confrontada apenas com regra de política tradicional estimada, mas também com uma Regra de Taylor ajustada ao spread, como será mostrado a seguir. 


\section{Regra de Política Monetária Respondendo aos Movimentos no Spread}

No contexto da economia dos EUA para o período logo após a crise financeira internacional, McCulley \& Toloui (2008) e Taylor et al. (2008) propuseram que se o Banco Central ajustasse a meta da taxa dos fed funds em resposta às mudanças nos spreads das taxas de crédito seria um avanço em relação à especificação clássica da regra de Taylor (1993), principalmente quando a origem dos choques exógenos que afetam a economia advém do setor financeiro. Assim, uma nova forma funcional para a regra de política monetária que levasse em consideração o spread e, assim reduzisse os desvios da taxa de juros básica da economia em relação à taxa pela qual os tomadores de crédito se financiam, poderia resultar em melhoras para a estabilização da economia.

A comparação entre a Regra de Taylor estimada anteriormente e a Regra Ótima para a política monetária revela que no caso de alguns tipos de choques exógenos a condução da política monetária com os parâmetros estimados difere daquela preconizada pela Regra Ótima. Nesse sentido, testamos a hipótese de Cúrdia \& Woodford (2010), McCulley \& Toloui (2008) e Taylor et al. (2008) de que se o Banco Central optar por uma regra de política monetária que leve em conta os movimentos no spread pode significar um avanço em relação à regra de política estimada para as perturbações exógenas que tem como origem o mercado financeiro.

Partindo da formulação geral da regra de política monetária, Cúrdia e Woodford (2010) propõem a seguinte forma para uma regra de política monetária ajustada pelo spread:

$$
i_{t}^{d}=\phi_{m} \hat{i}_{t-1}^{d}+\left(1-\phi_{m}\right)\left(\phi_{\pi} \pi_{t}+\phi_{y}\left(\hat{Y}_{t}-Y^{n}\right)-\phi_{\omega} \hat{\omega}_{t}\right)
$$

Na ausência de variações nos elementos que afetam especificamente o spread $\left(\Xi_{t}, \chi_{t}\right)$, a política acima será consistente com um equilíbrio no qual o hiato do produto e a taxa de inflação são completamente estabilizado e iguais a zero em todos os períodos. Esse resultado decorre da própria formulação da equação IS intertemporal e da relação de oferta agregada que são exatamente as mesmas do modelo Novo Keynesiano tradicional de Woodford \& Walsh (2003), apenas com a adição de termos que são função da evolução esperada do spread de crédito.

O coeficiente $0<\phi_{\omega}<1$ vai determinar o quanto da taxa de juros básica da economia vai ser influenciada pela variação no spread. As regras em que $\phi_{\omega}>$ 0 , significam que, tudo mais constante, a taxa básica da economia deve ser reduzida quando o spread aumenta. Quando $\phi_{\omega}=1$, a regra será equivalente a ter uma Regra de Taylor convencional para a taxa de juros dos empréstimos, em vez da taxa de juros básica que é tradicionalmente instrumentada pelo Banco Central. No outro extremo, quando $\phi_{\omega}=0$, corresponde à regra de política monetária tradicional sem considerar o spread.

Primeiramente, serão consideradas as perturbações originadas no sistema financeiro, sob diferentes valores para o parâmetro $\phi_{\omega}$. Os modelos com políticas alternativas serão comparados com os modelos com a regra de política monetária ótima e a regra de política monetária estimada. Será analisada duas fontes de perturbação para a função do spread (15), que podem ser via um choque na taxa de perda $\left(\chi_{t}\right)$, que é um choque puramente exógeno, ou na função 
de custo dos intermediários financeiros $\left(\Xi_{t}(b)\right)$, em que também sofrerá influência da variação no crédito agregado.

A Figura 7 mostra a resposta das variáveis do modelo a um aumento em $\chi_{t}$ de tal forma que o spread aumente em 1 p.p. a partir de uma situação de equilíbrio. No modelo básico com a regra de política monetária estimada (Modelo com F.F.) a perturbação leva não somente ao aumento no spread e contração no crédito agregado, como também a queda na atividade e na taxa de inflação. Porém, essa contração no produto é ineficiente, visto que na comparação com o modelo em que o Banco Central tem o compromisso com uma Regra Ótima (Modelo com F.F. e Regra Ótima) a recessão é menos intensa. Da mesma forma, a queda na taxa de inflação é menor no modelo com a Regra Ótima.

A simulação também mostra que o ajuste da política monetária ao spread pode remediar os inconvenientes do modelo com a Regra de Taylor estimada para esse tipo de choque, na medida em que a estabilização do produto e da inflação convergem ao equilíbrio numa velocidade maior. A contração do crédito agregado é menor sob qualquer das configurações propostas para $\phi_{\omega}$. Assim, a despesa agregada cai menos quando $\phi_{\omega}$ é positivo e as despesas de consumo dos tomadores de crédito já não retraem tanto, tendo em vista que a taxa de juros dos empréstimos tem seu crescimento reduzido em resposta ao crescimento no spread. E, nesse caso, o crédito agregado retrai menos, bem como o rendimento do trabalho também é menos afetado em resposta ao choque, pois o produto responde mais rapidamente de maneira positiva. Em resumo, os efeitos de ampliação e persistência do ciclo econômico decorrente do aumento no spread no modelo com fricções financeiras é mitigado com a nova regra de política monetária que leva em conta a variação no spread, uma vez que impede que a queda no crédito agregado realimente uma queda no produto.

No caso de um choque na função de custo dos intermediários $\left(\epsilon_{t}^{\Xi}\right)$ que aumenta em 1 p.p. no spread, podemos ver, assim como na simulação anterior, que a Regra de Taylor com spread pode obter sucesso para a estabilização da economia em comparação com as demais (Figura 8). Quando o Banco Central opera uma regra de política monetária tradicional, tanto ótima quanto com os parâmetros estimados, há um período mais longo de deflação e recessão determinado pela queda nas concessões de crédito.

Tanto o modelo com a regra de política monetária tradicional, quanto aquele com Regra Ótima, não conseguiram evitar a queda acentuada no crédito na economia em decorrência do aumento no spread. O afrouxamento na taxa de juros básica da economia não é suficiente para equilibrar a inflação e o produto, pois não consegue ajustar de maneira suficiente a taxa de juros dos empréstimos. Nesse caso, as regras de política monetária estimada (mais expansionista) e a Regra Ótima (mais contracionista) parecem menos eficazes para estabilizar a economia.

Por outro lado, a regra de política monetária com o componente para ajustar o aumento no spread entre as taxas de juros, assim como no exercício anterior, consegue estabilizar mais rapidamente a economia. Mais uma vez, esse maior sucesso decorre do efeito renda que a menor taxa básica produz sobre os agentes poupadores, que no caso do modelo com spread não é tão intenso, bem como da menor restrição ao consumo que é imposta para os agentes tomadores de crédito, pois a taxa pela qual os empréstimos são concedidos avança de maneira menos intensa quando o impacto do aumento do spread é suavizado.

A resposta do modelo a choques que não têm origem no mercado finan- 
Figura 7: Impulso e resposta em um choque em $\epsilon_{t}^{\chi}$, que aumenta o spread, $\omega(b)$, em 1 ponto percentual sob diferentes regras de política monetária

Produto (Y)
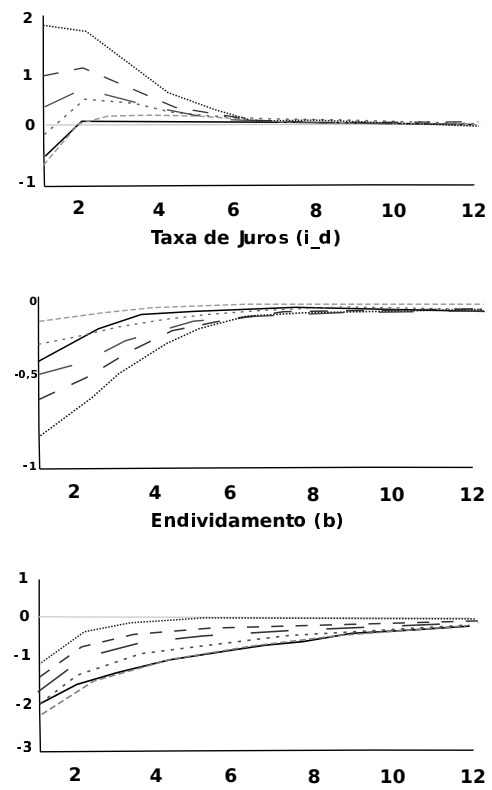

Fonte: Elaborado pelo autor.
Taxa de Inflação (pi)
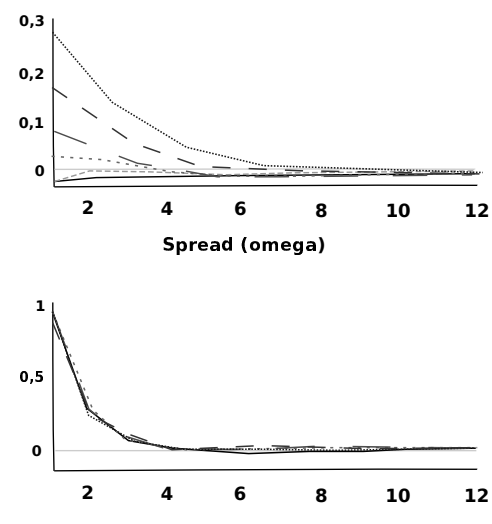

Modelo com F.F

Modelo com F.F e Regra Ótima

Modelo com F.F e Taylor+25

Modelo com F.F e Taylor+50

Modelo com F.F e Taylor +75

Modelo com F.F e Taylor+100

Figura 8: Impulso e resposta em um choque em $\epsilon_{t}^{\Xi}$, que aumenta o spread, $\omega(b)$, em 1 ponto percentual sob diferentes regras de política monetária
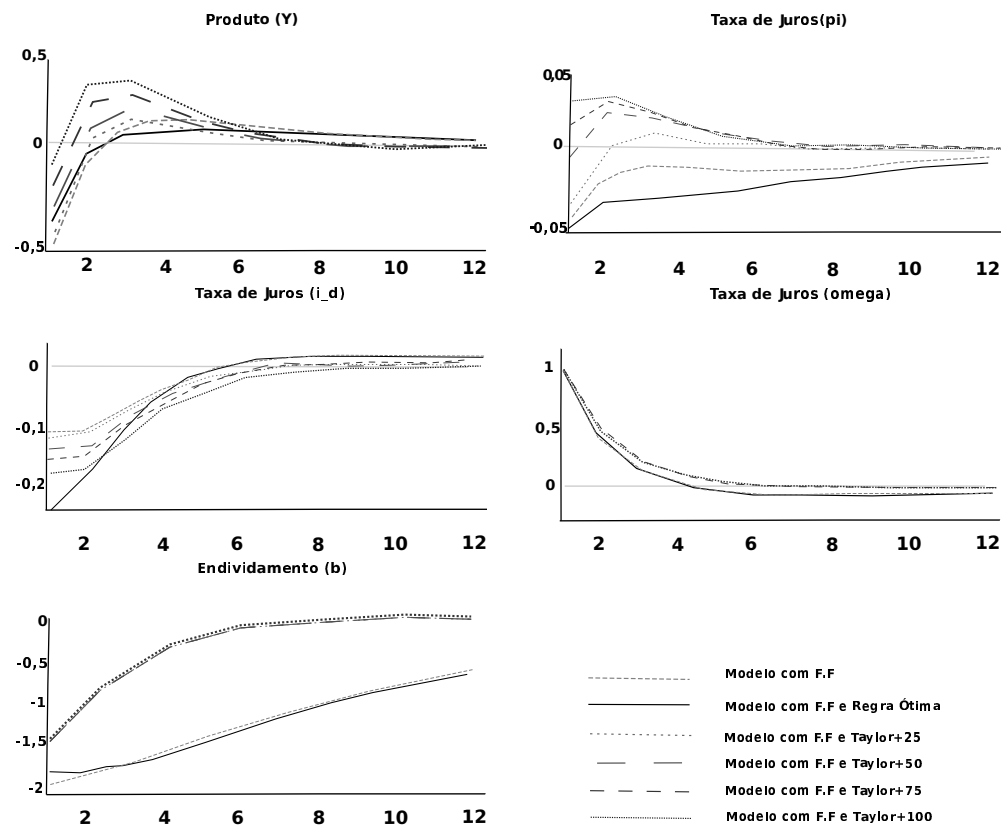

Modelo com F.F

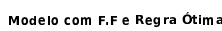

Modelo com F.F e Taylor+25

Modelo com F.F e Taylor +50

Modelo com F.F e Taylor+75

Modelo com F.F e Taylor +100

Fonte: Elaborado pelo autor. 
ceiro, por outro lado, mostra que a regra de política monetária com spread pode não ser a mais indicada. Um contraste em relação aos resultados obtidos para os choques no setor financeiro é verificado nos casos dos choques que afetam diretamente os componentes da demanda agregada.

A Figura 9 mostra a resposta do modelo a um choque de 1 ponto percentual na despesa de consumo dos agentes tomadores de crédito (tipo $b$ ). A resposta desse tipo de choque pelo modelo com Regra de Taylor é mais inflacionária do que o obtido pelo modelo com a regra de política monetária ótima. Além disso, o choque no consumo dos tomadores aumenta a demanda por crédito e, por conseguinte, o spread de crédito. Nos modelos em que a regra de política monetária é ajustada pelo spread, o ajuste positivo do spread resultará em aperto na taxa básica de juros menor do que o necessário para a estabilização da economia. Essa política afastará ainda mais do ajuste alcançado pela regra ótima.

A Figura 10 mostra o comportamento do modelo em resposta a um choque exógeno no dispêndio do setor público equivalente a 1 ponto percentual do PIB. Nesse choque, a política monetária tradicional e a política ótima apresentam um resultado bastante desinflacionário. A resposta do modelo a esse choque é similar ao obtido quando ocorre uma perturbação exógena na despesa de consumo das famílias poupadoras. O aumento na despesa, seja do governo ou das famílias poupadoras, reduzirá o crédito na economia via menor oferta de fundos para os intermediários e consequentemente diminuirá o spread de crédito de equilíbrio.

A política monetária responde de forma contracionista ao aumento no produto, impactando a taxa de inflação. Nesse caso, a regra de política monetária que responde ao spread produzirá um aperto monetário menor, favorecendo uma resposta mais positiva do produto. Porém, no caso em que $\phi_{\omega}=1$, há um processo inflacionário que persiste por diversos anos, o que prejudica a estabilização da economia. Assim, a regra de política monetária com o spread pode ser bastante ineficiente quando comparada com a Regra Ótima.

Normalmente, se espera que um aumento no dispêndio do setor público resulte em aumento de inflação. Porém, a queda na taxa de inflação verificada não decorre apenas do aperto na taxa de juros, mas também do efeito de alocação de recursos entre os agentes tomadores de crédito e que consomem uma proporção maior da sua renda para os agentes poupadores.

No caso de um choque não discricionário na oferta $\left(\epsilon_{t}^{Z}\right)$ que eleve a produtividade da economia, conforme mostra a Figura 11, percebe-se que a regra ótima para a política monetária é bastante desinflacionária em comparação com a regra estimada. Isso ocorre, pois o aumento do produto natural é menor do que o aumento no produto corrente, o que estimula uma resposta da política monetária, mais contundente, no caso da Regra Ótima.

Nos modelos com a regra de política monetária ajustada pelo spread, o aumento no spread provocado pela redução dos juros é atenuado, fazendo com que a taxa de juros básica seja colocada num patamar mais elevado, o que favorece a expansão do ciclo econômico. Por outro lado, as regras que levam em conta o spread tendem a gerar uma trajetória mais elevada para a taxa de inflação, o que seria mais problemático numa situação em que ocorre uma queda na produtividade. 
Figura 9: Respostas dos modelos ao choque de 1 ponto percentual na despesa de consumo dos agentes do tipo $b$

Produto $(Y)$
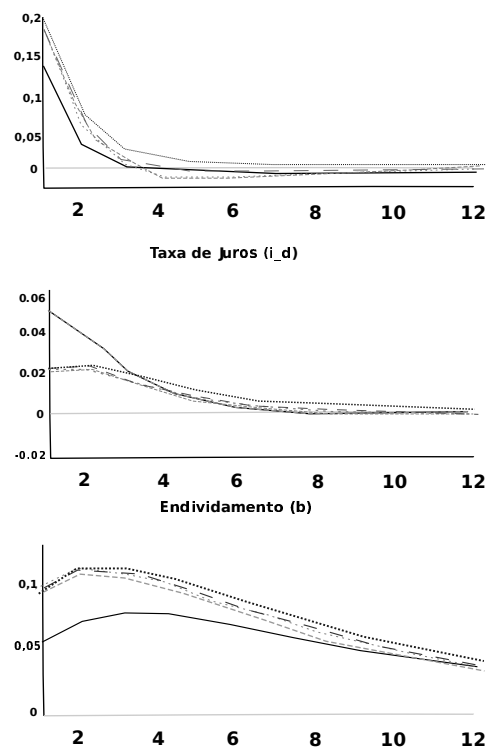

Fonte: Elaborado pelos autores.
Taxa de Inflação (pi)
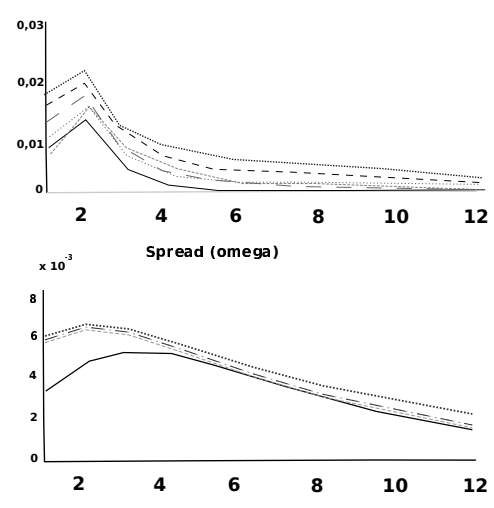

Modelo com F.F

Modelo com F.F e Regra ótim

Modelo com F.F e Taylor+25

Modelo com F.F e Taylor+50

Modelo com F.F e Taylor +75

Modelo com F.F e Taylor+100

Figura 10: Resposta dos modelos ao choque de choque de 1 ponto percentual do PIB no gasto público $\left(\epsilon_{t}^{g}\right)$
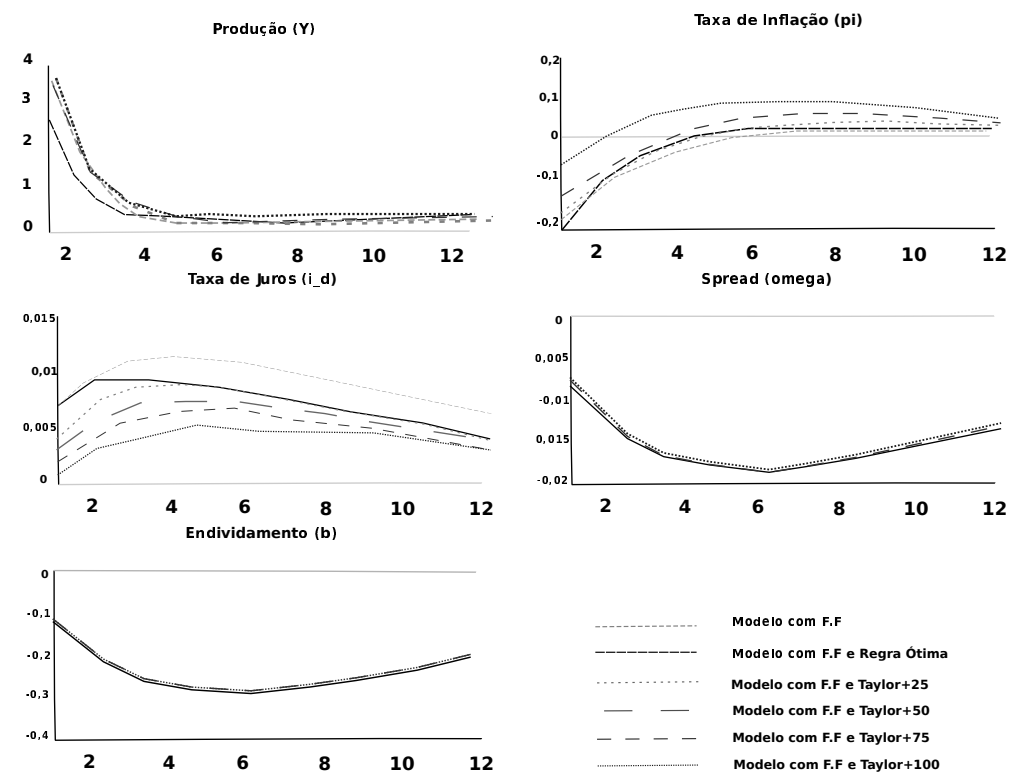

Fonte: Elaborado pelos autores. 
Figura 11: Resposta dos modelos ao choque de choque de 1 desvio padrão na produtividade $\left(\epsilon_{t}^{Z}\right)$
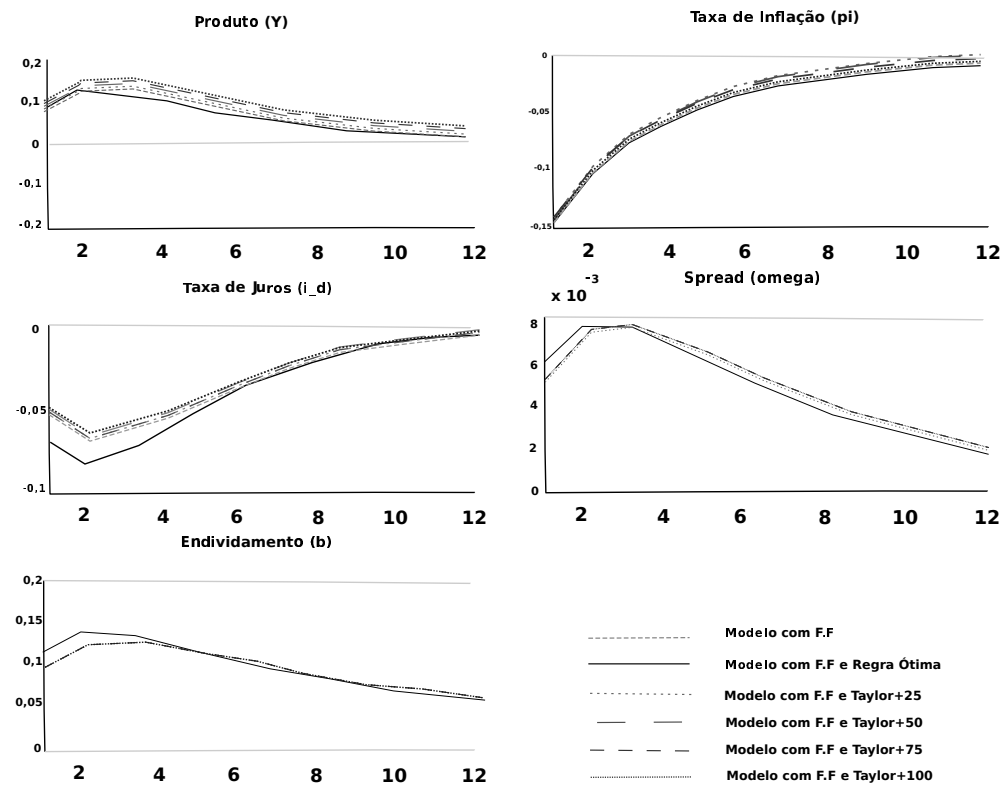

Fonte: Elaborado pelos autores.

\section{Considerações finais}

O desenvolvimento dos modelos DSGE tem buscado acrescentar elementos para modelar os diferentes tipos de rigidez e fricções que são observados nos mercados. A crise internacional de 2008 expôs a fragilidade desses modelos em mimetizar os movimentos no mercado financeiro e seus impactos no lado real da economia. Para isso, a adoção de estruturas mais complexas abre espaço para que diferentes tipos de política econômica sejam testadas.

Nesse contexto, a expansão do crédito na economia brasileira aumenta o potencial de que caso ocorra uma crise localizada no setor financeiro, a economia seja severamente atingida. As simulações do modelo mostram que a deterioração da intermediação financeira terá grandes efeitos adversos sobre a atividade. E, nesse ambiente, a política monetária tradicional pode enfrentar grande dificuldade para estabilizar a economia. Essa situação pode ser verificada na simulação do choque na função de custo dos intermediários (Figura 6), em que há um período mais longo de deflação e recessão determinado pela queda nas concessões de crédito quando a política monetária tradicional é aplicada.

Contudo, a política monetária ajustada pelo spread, que é eficaz para diminuir os ciclos recessivos no caso dos choques exógenos sobre a intermediação, pode ser problemático para outros tipos de choques. Assim, os resultados também apontam que a política monetária tradicional permanece adequada no modelo com friç̧ões financeira e que a política monetária ótima permanece simples para a maioria dos choques tradicionais (gastos do governo e choque tecnológico).

As conclusões desse trabalho são um avanço pequeno e o modelo utilizado contém diversas limitações por conta da sua simplicidade. Por exemplo, o mo- 
delo deixa o lado da produção em segundo plano, que permanece semelhante ao modelo Novo Keynesiano tradicional, e mantém foco na intermediação entre as famílias e não entre as famílias e as firmas diretamente. Então, uma diminuição do crédito na economia faz com que algumas famílias consumam mais e trabalhem menos e outras consumam menos e trabalhem mais. Contudo, não há impacto direto da redução do crédito sobre a produção. Por exemplo, supondo que o processo de produção aconteça em mais de um período e as firmas precisam tomar empréstimos para comprar insumos. Nesse caso, tudo mais constante, uma queda no crédito resultará em menor produção. Um avanço importante para a literatura seria acrescentar as friç̧ões financeiras também no setor produtivo para avaliar o impacto do spread na decisão de produção e investimento das firmas.

Outra limitação importante do trabalho refere-se às informações sobre o comportamento dos tipos de famílias, o que pode ser um importante melhoramento do modelo. O modelo faz uma suposição forte para estimar a proporção do consumo na renda e as elasticidades substituição do consumo das famílias poupadoras e tomadoras com base nas estimativas para os valores agregados. Porém, o mais indicado seria estimar esses parâmetros com base em séries sobre o perfil de consumo de cada agente. Outra possibilidade seria a calibragem com dados com base em informações sobre cada tipo de agente. Essa diferenciação entre os tipos de agentes talvez possa ser encontrada em pesquisas e artigos sobre as características da população e do consumidor ou até mesmo utilizando informações do Censo e da Pesquisa Nacional por Amostra de Domicílios.

\section{Referências Bibliográficas}

Afanasieff, T. S., Lhacer, P. M., Nakane, M. I. et al. (2002), 'The determinants of bank interest spread in Brazil', Money Affairs 15(2), 183-207.

An, S. \& Schorfheide, F. (2007), 'Bayesian analysis of DSGE models', Econometric Reviews 26(2-4), 113-172.

Aragón, E. K. d. S. B. \& Portugal, M. S. (2009), 'Central bank preferences and monetary rules under the inflation targeting regime in Brasil', Brazilian Review of Econometrics 29(1), 79-109.

Aranha, M. Z. (2012), Um modelo DSGE com fricções financeiras aplicado ao Brasil, PhD thesis, Universidade de São Paulo.

Aronovich, S. (1994), 'Uma nota sobre os efeitos da inflação e do nível de atividade sobre o spread bancário', Revista Brasileira de Economia 48(1), 125140 .

Benigno, P. \& Woodford, M. (2005), 'Inflation stabilization and welfare: the case of a distorted steady state', Journal of the European Economic Association 3(6), 1185-1236.

Bernanke, B. S. \& Gertler, M. (1989), 'Agency costs, net worth, and business fluctuations', American Economic Review 79(1), 14-31.

Bernanke, B. S., Gertler, M. \& Gilchrist, S. (1999), 'The financial accelerator in a quantitative business cycle framework', Handbook of Macroeconomics 1, 1341-1393. 
Brooks, S. P. \& Gelman, A. (2012), 'General methods for monitoring convergence of iterative simulations', Journal of Computational and Graphical Statistics 7(4), 434-455.

Carvalho, F., Castro, M. \& Costa, S. (2013), 'Traditional and matter-of-fact financial frictions in a DSGE model for Brazil: the role of macroprudential instruments and monetary policy'.

Castro, M. R., Gouvea, S. N., Minella, A., Santos, R. \& Souza-Soubrinho, N. F. S. (2011), Stochastic analytical model with a Bayesian approach, Technical report, Banco Central do Brasil, Working Papers Series.

Costa, S. M. d. A. (2011), Intervenções do Estado sobre o mercado bancário e os trade-offs entre eficiência, resiliência financeira e estabilidade macroeconômica, PhD thesis, Universidade de São Paulo.

Cúrdia, V. \& Woodford, M. (2009), 'Credit frictions and optimal monetary policy', Journal of Monetary Economics 84, 30-65.

Cúrdia, V. \& Woodford, M. (2010), 'Credit spreads and monetary policy', Journal of Money, Credit and Banking 42(s1), 3-35.

De Fiore, F. \& Tristani, O. (2011), 'Credit and the natural rate of interest', Journal of Money, Credit and Banking 43(2-3), 407-440.

DeJong, D. N. \& Dave, C. (2011), Structural Macroeconometrics, Princeton University Press.

Gertler, M. \& Karadi (2011), 'A model of unconventional monetary policy', Journal of Monetary Economics 58(1).

Goodfriend, M. \& McCallum, B. T. (2007), 'Banking and interest rates in monetary policy analysis: a quantitative exploration', Journal of Monetary Economics 54(5), 1480-1507.

Iskrev, N. (2010), 'Local identification in DSGE models', Journal of Monetary Economics 57(2), 189-202.

Kanczuk, F. (2013), 'Um termômetro para as macro-prudenciais', Revista Brasileira de Economia 67(4), 497-512.

McCulley, P. \& Toloui, R. (2008), 'Chasing the neutral rate down: financial conditions, monetary policy, and the Taylor rule', Global Central Bank Focus pp. 2002-2008.

Nunes, A. \& Portugal, M. S. (2015), Modelo DSGE com intermediários financeiros e política monetária não convencional, in ' $37^{\circ}$ Encontro Brasileiro de Econometria'.

Rotemberg, J. J. \& Woodford, M. (1997), 'An optimization-based econometric framework for the evaluation of monetary policy', NBER Macroeconomics Annual 12, 297-346.

Santin, R. R. M. (2013), Análise da política de crédito do BNDES em um modelo DSGE, PhD thesis. 
Stéphane, A., Bastani, H., Juillard, M., Mihoubi, F., Perendia, G., Ratto, M. \& Villemot, S. (2011), 'Dynare: reference manual, version 4'.

Taylor, J. (1993), 'Discretion versus policy rules in pratice'.

Taylor, J. B. et al. (2008), 'Monetary policy and the state of the economy', Testimony Before the Committee on Financial Services, US House of Representatives

Vasconcelos, B. \& Divino, J. A. (2012), 'O desempenho recente da política monetária brasileira sob a ótica da modelagem DSGE', Banco Central do Brasil, pp. 1-36.

Vega Filho, J. A. C. (2013), 'Intermediação financeira e ciclos reais: uma abordagem DSGE para a economia brasileira'.

Woodford, M. (2010), 'Financial intermediation and macroeconomic analysis', Journal of Economic Perspectives 24(4), 21-44.

Woodford, M. \& Walsh, C. E. (2003), 'Interest and prices: foundations of a theory of monetary policy', Macroeconomic Dynamics 9(3), 462-468. 


\section{Apêndice A Relações de Equilíbrio do Modelo}

O modelo é composto pelas Equações log-linearizadas (5), (6), (12), (13) e (15)-(28). Além disso, completam o modelo e as seguintes relações de equilíbrio e estado estacionário:

$$
\begin{aligned}
& \mu_{p}=\frac{\theta}{\theta-1} \\
& s_{c} \bar{c}_{t}=\pi_{b} s_{b}+\left(1-\pi_{b}\right) s_{s} \\
& \bar{\sigma}=\pi_{b} s_{b} \sigma_{b}+\left(1-\pi_{b}\right) s_{s} \sigma_{s} \\
& \bar{c}_{b}=s_{b}\left(\bar{\Sigma} \lambda^{s}\right)^{\sigma_{b}} \\
& \bar{c}_{s}=s_{s}\left(\lambda^{s}\right)^{\sigma_{s}} \\
& \bar{\Sigma}=\frac{1-\left(1-\bar{r}^{d} \beta\left[\delta+(1-\delta)\left(1-\pi_{b}\right)\right]\right)}{\left(1-\bar{r}^{d}\right) \beta(1-\delta) \pi_{b}} \\
& \lambda^{s}=\psi_{s} \mu_{p}\left(1+\omega_{y}\right)\left(\overline{\mu_{w}}\right) /(1-\bar{\tau}) \\
& \bar{\lambda}=\left(\pi_{b} \bar{\Sigma}^{-\frac{1}{v}}+\left(1+\pi_{b}\right)^{-v}\right) \lambda^{s} \\
& i^{d}=\frac{\beta^{-1}}{2 \delta(1+\bar{\omega})}\left[(\delta+1)+\bar{\omega}\left(\delta+(1-\delta) \pi_{b}-(\delta+1)+\right.\right. \\
& \left.\left.\bar{w}\left(\delta+(1-\delta) \pi^{2}\right)^{2}-4 \delta(1-\bar{\omega})\right)\right] \\
& \psi_{s}=\psi\left(\pi_{b} \bar{\Sigma}^{-\frac{1}{v}}+(1-\pi+b)^{v}\right) \\
& \omega_{y}=\phi(1-v)-1 \\
& s_{\Xi}=\frac{\bar{\omega}}{\eta b_{Y}} \\
& s_{g}=1-s_{c}-s_{\Xi} \\
& s_{\Sigma}=\pi_{b}\left(1-\pi_{b}\right)\left(s_{b} \sigma_{b}-s_{s} \sigma_{s}\right) / \bar{\sigma} \\
& \xi=\frac{1-\alpha}{\alpha} \frac{1-\alpha \beta}{1+\omega_{y} \theta} \\
& \Xi=\frac{\bar{\omega}}{\left(\eta b_{Y}\right)^{\eta-1}} \\
& \kappa=\xi\left(\omega_{y}+\bar{\sigma}^{-1}\right)
\end{aligned}
$$




$$
\begin{gathered}
\omega_{b}=\frac{\eta(\eta-1) s_{\Xi}}{1+\omega} \\
\omega_{\chi}=\frac{1}{1+\bar{\omega}} \\
\omega_{\Xi}=\eta b_{Y} /(1+\bar{\omega}) \\
\tilde{B}_{\Sigma}=\psi \tilde{\lambda} \bar{\mu}_{\omega} \\
B_{\Sigma}=s_{\Sigma} \pi_{b}-s_{b} \sigma_{b} \pi_{b}\left(1-\pi_{b}\right)-\tilde{B}_{\omega}
\end{gathered}
$$

Parâmetros para a equação de evolução da dívida:

$$
\begin{gathered}
\rho_{r}=\frac{\delta\left(1+\bar{r}^{d}\right)}{1+\pi_{b} \bar{\omega}}\left[(1+\bar{\omega})+\frac{\pi_{b} \bar{b}^{g}}{\bar{b}}\right] \\
\rho_{\xi}=\frac{b_{Y}}{1+\pi_{b} \bar{\omega}} \\
\rho_{Y}=\rho_{\xi} s_{\Sigma} \bar{\sigma}^{-1} \\
\rho_{\Sigma}=\rho_{\xi}\left(B_{\Sigma}+s_{\Sigma}^{2}\right) \\
\rho_{\omega}=\frac{\pi_{b}(1+\bar{\omega})}{1+\pi_{b} \bar{\omega}} \\
\rho_{b}=\frac{\delta\left(1+\bar{r}^{d}\right)(1+\bar{\omega})}{1+\pi_{b} \bar{\omega}}
\end{gathered}
$$

\section{Apêndice B Parâmetros da Função para a Política Ótima}

A derivação da função de perda para o Banco Central e para o modelo de Cúrdia \& Woodford (2010) pode ser verificada no trabalho original. Abaixo são apresentados os parâmetros da função $\left(\lambda_{y}, \lambda_{\Sigma}, \lambda_{\Xi}>0\right)$ e a relação para o produto natural com o setor de intermediação $\left(\hat{Y}_{t}^{*}\right)$.

$$
\begin{gathered}
\lambda_{y}=\frac{\xi}{\theta} \omega_{y} \\
\lambda_{\Sigma}=\frac{\xi}{\theta} \bar{\lambda}_{\Sigma} \\
\tilde{\lambda}_{\Sigma}=\frac{\left[\pi_{b} s_{b} \sigma_{b}\right]\left[\left(1-\pi_{b}\right) s_{s} \sigma_{s}\right]}{\bar{\sigma}}+\frac{\pi_{b}\left(1-\pi_{b}\right)}{v\left(1+\omega_{y}\right)} \\
\lambda_{\Xi}=2 \eta \frac{\xi}{\theta} \\
\hat{Y}_{t}^{*}=\hat{Y}_{t}^{n}+\frac{\sigma^{-1}}{\omega_{y}+\bar{\sigma}^{-1}} \tilde{\Xi}_{t}
\end{gathered}
$$




\section{Apêndice C Teste para Identificação dos Parâmetros Estimados}

Resultado para o teste de Iskrev (2010).

Figura C.1: Teste para identificação dos parâmetros estimados
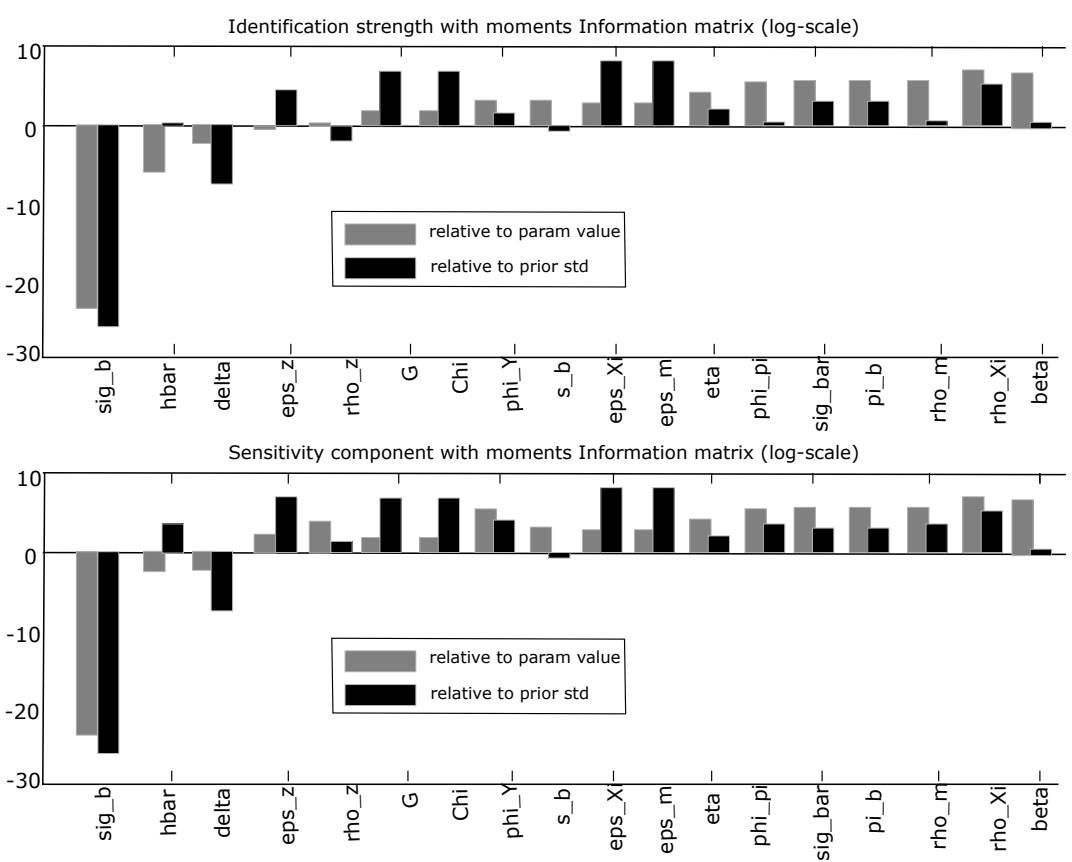

Fonte: Elaborado pelos autores. 
